\title{
¿Cutoff Lows, Moisture Plumes, and Their Influence on Extreme-Precipitation Days in Central Chile
}

\author{
CRISTIAN MUÑOZ ${ }^{\mathrm{a}}$ AND DAVID M. SCHUltz ${ }^{\mathrm{a}, \mathrm{b}}$ \\ ${ }^{\text {a } C e n t r e ~ f o r ~ A t m o s p h e r i c ~ S c i e n c e, ~ S c h o o l ~ o f ~ E a r t h ~ a n d ~ E n v i r o n m e n t a l ~ S c i e n c e s, ~ U n i v e r s i t y ~ o f ~ M a n c h e s t e r, ~ M a n c h e s t e r, ~ U n i t e d ~ K i n g d o m ~}$ \\ ${ }^{\mathrm{b}}$ Centre for Crisis Studies and Mitigation, University of Manchester, Manchester, United Kingdom
}

(Manuscript received 13 June 2020, in final form 21 January 2021)

\begin{abstract}
A study of 500-hPa cutoff lows in central Chile during 1979-2017 was conducted to contrast cutoff lows associated with the lowest quartile of daily precipitation amounts (LOW25) with cutoff lows associated with the highest quartile (HIGH25). To understand the differences between low- and high-precipitation cutoff lows, daily precipitation records, radiosonde observations, and reanalyses were used to analyze the three ingredients necessary for deep moist convection (instability, lift, and moisture) at the eastern and equatorial edge of these lows. Instability was generally small, if any, and showed no major differences between LOW25 and HIGH25 events. Synoptic-scale ascent associated with Q-vector convergence also showed little difference between LOW25 and HIGH25 events. In contrast, the moisture distribution around LOW25 and HIGH25 cutoff lows was different, with a moisture plume that was more defined and more intense equatorward of HIGH25 cutoff lows as compared with LOW 25 cutoff lows where the moisture plume occurred poleward of the cutoff low. The presence of the moisture plume equatorward of $\mathrm{HIGH} 25$ cutoff lows may have contributed to the shorter persistence of HIGH 25 events by providing a source for latent-heat release when the moisture plume reached the windward side of the Andes. Indeed, whereas $48 \%$ of LOW 25 cutoff lows persisted for longer than $72 \mathrm{~h}$, only $25 \%$ of HIGH 25 cutoff lows did, despite both systems occurring mostly during the rainy season (May-September). The occurrence of an equatorial moisture plume on the eastern and equatorial edge of cutoff lows is fairly common during high-impact precipitation events, and this mechanism could help to explain high-impact precipitation where the occurrence of cutoff lows and moisture plumes is frequent.
\end{abstract}

KEYWORDS: South America; Cutoff lows; Rossby waves; Precipitation; Orographic effects; Atmospheric river

\section{Introduction}

Cutoff lows are closed upper-level low pressure systems that detach from the main westerlies, mostly by Rossby wavebreaking events (e.g., Ndarana and Waugh 2010) or by stratospheric air intrusions from the polar reservoir to midlatitudes through tropopause folds (e.g., Keyser and Shapiro 1986; Price and Vaughan 1993; Wernli and Sprenger 2007). The spatial distribution of cutoff lows varies with latitude. In the subtropics and midlatitudes, cutoff lows occur mostly over continents and adjacent oceans, whereas at high latitudes they are more likely to occur over the oceans, with fewer events occurring directly over the storm tracks (e.g., Nieto et al. 2005; Fuenzalida et al. 2005; Nieto et al. 2008; Reboita et al. 2010; Pinheiro et al. 2017; Muñoz et al. 2020).

Cutoff lows enclose colder air from higher latitudes. Because cold air in the middle and upper troposphere destabilizes the atmosphere, when cutoff lows reach midlatitudes they can be associated with a variety of weather phenomena. For instance, cutoff lows can bring unusually cold conditions to high-elevation regions (Vuille and Ammann 1997) and increase the ozone

๑ Denotes content that is immediately available upon publication as open access.

Muñoz's current affiliation: Centro de Estudios Avanzados en Zonas Áridas (CEAZA), La Serena, Chile.

Corresponding author: Prof. David M. Schultz, david.schultz@ manchester.ac.uk concentration in the lower troposphere (e.g., Davies and Schuepbach 1994; Ancellet et al. 1994; Rondanelli et al. 2002; Barrett et al. 2019). Cutoff lows can also be associated with the initiation of convection and heavy precipitation (e.g., Griffiths et al. 1998; Massacand et al. 1998; Miky-Funatsu et al. 2004; Singleton and Reason 2007; Porcù et al. 2007; Hu et al. 2010; Shepherd et al. 2011), provided the ingredients are in place for the development of deep moist convection (instability, lift, and moisture; e.g., McNulty 1978; Doswell 1987; Johns and Doswell 1992; McNulty 1995; Doswell et al. 1996).

In southwestern South America, arriving cutoff lows can be responsible for $10 \%-40 \%$ of the mean annual precipitation in northern and central Chile (Pizarro and Montecinos 2000; Barahona 2016), where most precipitation results from the passage of cold fronts associated with extratropical cyclones, especially poleward of $30^{\circ} \mathrm{S}$ between May and September (Falvey and Garreaud 2007). The $10 \%-40 \%$ of the annual precipitation associated with the arrival of cutoff lows might be explained by lower-tropospheric frontogenesis (e.g., Hoskins et al. 1985) and the arrival of moisture plumes to the eastern edge of the cutoff low, a region of these lows where convective storms tend to form (e.g., Antonescu et al. 2013; Vaughan et al. 2017). If the adjacent southeastern Pacific Ocean is anomalously warm during the arrival of a cutoff low, convection is further favored and heavy-precipitation

This article is licensed under a Creative Commons Attribution 4.0 license (http://creativecommons.org/ licenses/by/4.0/). 
events are more likely to occur (Barrett et al. 2016; Bozkurt et al. 2016).

A moisture plume is a long, narrow, and transient corridor of strong horizontal water-vapor transport from lower latitudes. When a moisture plume satisfies certain conditions with regard to length, width, and the strength of the horizontal vapor transport throughout the air column that depend on the region of interest (Guan and Waliser 2015), then it is called an atmospheric river (e.g., Ralph et al. 2004; Cordeira et al. 2013; Guan et al. 2018; American Meteorological Society cited 2020). In this article, we will use the term "moisture plume" for this feature, regardless of whether it meets the quantitative criteria for being an atmospheric river.

In areas where 500-hPa cutoff lows are frequent, the subgroup of moisture plumes categorized as atmospheric rivers can explain $30 \%-60 \%$ of the annual precipitation (e.g., Lamjiri et al. 2017; Blamey et al. 2018; Viale et al. 2018). However, studies associating extreme-precipitation events with the presence of moisture plumes around cutoff lows are mostly limited to independent case studies (e.g., Hirota et al. 2016; Bozkurt et al. 2016), although a recent study by Tsuji and Takayabu (2019) suggests the interplay between cutoff lows and atmospheric rivers is key for explaining heavy-precipitation events in Japan. A recent study by Valenzuela and Garreaud (2019) presents the linkage between atmospheric rivers and heavy precipitation in Chile. Thus, the link between cutoff lows and moisture plumes in initiating heavy-precipitation events, specifically in central Chile, is still unresolved climatologically.

Hence, this article aims to characterize the link between moisture plumes and cutoff lows affecting central Chile and how this link influences precipitation associated with cutoff lows. Specifically, as not all cutoff lows are associated with heavy precipitation, we investigate this link for two groups of cutoff lows: those lows associated with low daily precipitation amounts in central Chile and those lows associated with high daily precipitation amounts in central Chile. Once we define both groups, we compare their persistence and establish the synoptic-scale features that lead to their occurrence.

This article is organized as follows. Section 2 describes the datasets and methods used to conduct our research. Section 3 describes South American cutoff lows based on the horizontal distribution of the precipitable-water anomaly with respect to the annual cycle and also on the 500-hPa geopotential height distribution around cutoff lows; it also describes the criteria to categorize cutoff lows affecting central Chile into low- and highprecipitation cutoff lows. Section 4 examines the presence and release of instability by ascent and the moisture distribution around cutoff lows in these two categories and also discusses how this moisture distribution and the splitting of the westerlies around cutoff lows are key for differentiating between the two categories. Section 5 exemplifies the development of the two categories of cutoff lows through two case studies, and section 6 summarizes this article and provides ideas for further research.

\section{Data and methods}

Because nearly two-thirds of Chile's inhabitants live in central Chile and are impacted by heavy precipitation, we used
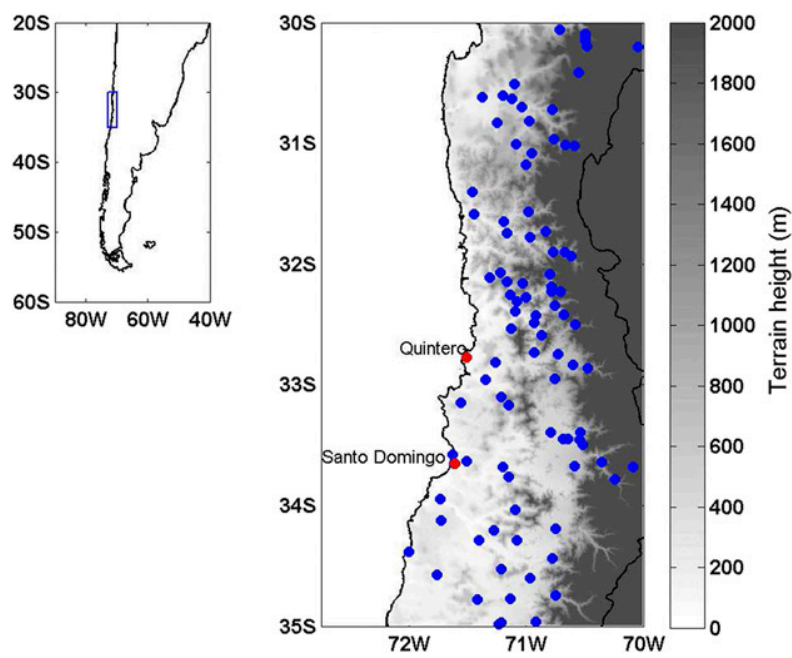

FIG. 1. Study region (blue-outlined rectangle in the inset) and spatial distribution of the 94 stations with daily precipitation gauges (blue dots) and radiosonde stations (red dots). Terrain height $(\mathrm{m})$ is shaded.

24-h accumulated precipitation data recorded in central Chile $\left(30^{\circ}-35^{\circ} \mathrm{S}\right)$ during $1979-2017$. These data are compiled by the Center for Climate and Resilience Research (CR2) from a precipitation-gauge network of 256 stations recorded in central Chile $\left(30^{\circ}-35^{\circ} \mathrm{S}\right)$ managed by the Dirección General de Aguas (DGA) or the Dirección Meteorológica de Chile (DMC). From the 256 stations available, we used only the 94 stations that had fewer than 5\% of missing data during 1979-2017 (Fig. 1).

To characterize the local environment during the passage of a cutoff low, we used radiosonde observations available from the archive of the University of Wyoming. The radiosondes were usually launched twice daily at Quintero $\left(32.77^{\circ} \mathrm{S}\right.$, $\left.71.51^{\circ} \mathrm{W} ; 8 \mathrm{~m} \mathrm{AGL}\right)$ before September 1998 and at Santo Domingo $\left(33.65^{\circ} \mathrm{S}, 71.61^{\circ} \mathrm{W} ; 75 \mathrm{~m}\right.$ AGL) after September 1998. The shift in station location does not affect the values of meteorological variables during precipitation events (Falvey and Garreaud 2007, p. 175), so all available soundings were treated as if they came from the same station. One of the variables available from the soundings is the convective available potential energy (CAPE). CAPE measures the susceptibility of a given temperature and moisture profile to the occurrence of convection (Holton 2004, p. 295), a phenomenon widely associated with the passage of cutoff lows (as discussed in section 1). CAPE is calculated using an air parcel that ascends dry adiabatically from the lowest $500 \mathrm{~m}$ of the atmosphere to the lifting condensation level and moist adiabatically thereafter, beyond its level of free convection until it reaches the level of neutral buoyancy, at which the temperature of the ascending air parcel is equal to the environmental temperature.

We also used reanalysis fields to characterize the synoptic environment of cutoff lows. These fields consist of 500-hPa geopotential height and precipitable water plus horizontal and vertical wind and water-vapor mixing ratio at all isobaric levels available between 1000 and $300 \mathrm{hPa}$, extracted every $6 \mathrm{~h}$ from the National Centers for Environmental Prediction-National 



FIG. 2. Composite of precipitable-water anomaly with respect to the annual cycle (shaded), 500-hPa geopotential height composite (solid contours; dam), and 850-hPa geopotential height composite (dotted contours; dam) based on 991 South American cutoff lows detected during 1979-2017. The composites are shown for the following times: (a) $24 \mathrm{~h}$ before the cutoff low is detected for the first time, (b) at time $T_{0}$, when the cutoff low is first detected, (c) $24 \mathrm{~h}$ after the first detection, (d) $48 \mathrm{~h}$ after the first detection, and (e) $72 \mathrm{~h}$ after the first detection. M1 and M2 indicate the moist areas around the cutoff-low center [black dot in (b)], and D1 indicates the dry area between the moist areas. Latitudes and longitudes are relative to the low center at $T_{0}$.

Center for Atmospheric Research (NCEP-NCAR) reanalysis (Kalnay et al. 1996). This reanalysis has a horizontal grid spacing of $2.5^{\circ}$ latitude-longitude and was also used for identifying the presence of moisture plumes by computing integrated vapor transport (IVT) at each grid point as

$$
\mathrm{IVT}=\frac{1}{g} \int_{1000 \mathrm{hPa}}^{300 \mathrm{hPa}} q \mathbf{V} d p,
$$

where $\mathbf{V}=(u, v)$ is the horizontal wind vector, $q$ is water-vapor mixing ratio, $p$ is the pressure, and $g$ is the gravitational acceleration $\left(9.81 \mathrm{~m} \mathrm{~s}^{-1}\right)$. Last, we used the cutoff-low detection algorithm employed in Reboita et al. (2010) and Muñoz et al. (2020) to extract all 500-hPa cutoff lows that occurred in South America and the adjacent southeast Pacific Ocean $\left(20^{\circ}-50^{\circ} \mathrm{S}\right.$, $120^{\circ}-30^{\circ} \mathrm{W}$ ) during $1979-2017$. This detection algorithm is based on the conceptual model of a cutoff low described in Nieto et al. (2005), which characterizes a cutoff low as a coldcore closed cyclonic circulation detached from the main westerlies with a thickness ridge and a highly baroclinic edge at the low's eastern flank. The reason we chose this algorithm is because its implementation is relatively simple while being consistent with previous works (e.g., Reboita et al. 2010; Muñoz et al. 2020) and because a more elaborate method such 
as analyzing isolated potential vorticity anomalies, despite being more useful for establishing the stratospheric origin of the cutoff low, might detect structures associated with local heating rather than stratospheric-air incursions to midlatitudes (e.g., Wernli and Sprenger 2007).

\section{Cutoff lows and their associated precipitation along the western coast of South America}

\section{a. Mean structure}

Despite our focus on categorizing 500-hPa cutoff lows affecting central Chile, we begin with a broader view by characterizing the mean structure of the 991500 -hPa cutoff lows that occurred over South America and the adjacent southeastern Pacific Ocean during 1979-2017. These lows were likely to occur at any season, but they tended to be most frequent during austral autumn and austral winter (Muñoz et al. 2020), with a life cycle and structure described as follows. As the parent trough formed (Fig. 2a), three synoptic-scale features appeared around the center of the future cutoff low: two areas of positive precipitable-water anomalies (or moist areas, referred to as M1 and M2) and one area of negative anomalies between them (or dry area, referred to as D1), consistent with Fig. 5 in Favre et al. (2012). As the veering of the geostrophic wind suggests, the regions M1 and M2 were located within regions of warm and moist air advection, while D1 was located within a region of cold and dry air advection associated with backing of the geostrophic wind, consistent with the intrusion of dry upper-tropospheric and stratospheric air typical of cutoff lows (Nieto et al. 2008).

As the cutoff low developed and moved eastward (Figs. 2b-d), D1 and M1 rotated cyclonically around the upper-level low, with M1 located at the eastern (or downstream) edge and D1 at the western (or upstream) edge. There was no composite closed low at the time representing the formation of cutoff lows (Fig. 2b), a consequence of the smoothing effect of the temporal average and the specific contours drawn.

Upstream of the precipitable-water anomaly dipole, the third feature (M2) appeared as an elongated moist area (Figs. 2a-c), which was usually associated with a cold front arriving after the cutoff low (Nieto et al. 2005; Favre et al. 2012). This three-part structure weakened as the low developed further and M2 moved eastward, until M1 and M2 merged around $72 \mathrm{~h}$ after the low formation, isolating the dry area from its polar origin as the low dissipated and the upper-level flow returned to be mostly zonal (Fig. 2e). As cutoff lows are often associated with tropopausefolding events (e.g., Price and Vaughan 1993; Appenzeller et al. 1996), D1 was likely a consequence of subsidence into the upperlevel low. On the other hand, provided there was enough lifting to release the instability, M1 favored convection at the upperlevel low's equatorial and eastern border (herein "leading edge"). Indeed, Antonescu et al. (2013) and Vaughan et al. (2017) showed that the eastern flank of an upper-level trough, from which cutoff lows form, favors convective storm formation associated with tropopause folds.

Because M2 was mostly associated with cold fronts arriving after the cutoff low, M1 was the area where precipitation strictly associated with cutoff lows occurred. In South American cutoff lows, M1 extended around $20^{\circ}$ eastward and $20^{\circ}$ equatorward from the upper-level low's center (Fig. 2b), in agreement with the precipitable-water anomaly distribution described in Favre et al. (2012). Because these lows tend to be slowly moving features (Fuenzalida et al. 2005), whenever M1 was over central Chile and the adjacent southeastern Pacific Ocean $\left(90^{\circ}-70^{\circ} \mathrm{W}\right)$ during a precipitation day, the associated upper-level low was retained for further analyses. These analyses will be the basis to define each category of cutoff low affecting central Chile.

\section{b. Definition of cutoff-low categories affecting central Chile}

We identified 1321 days with precipitation at $25 \%$ or more of the 94 stations during 1979-2017. For each of these 1321 days, we computed the average amount of precipitation per station and retained the lower- and upper-quartiles of the so-formed distribution. The retention of the days belonging to each extreme quartile was to make sure we extracted enough days that were not only associated with "bottom 25\%" and "top 25\%" precipitation, but days where the amount of precipitation in central Chile was more likely to be associated with low impact and high impact, respectively. As a result, we retained the 330 days on which the average precipitation per station was less than $6.26 \mathrm{~mm}$ (LOW25 days) and the 330 days on which the average precipitation per station was above $18.97 \mathrm{~mm}$ (HIGH25 days). We next looked for the occurrence of a 500-hPa cutoff low. In 166 days of the total of 1321 days, the leading edge of a 500-hPa cutoff low (M1 in Fig. 2) affected central Chile and the adjacent southeastern Pacific Ocean (i.e., the leading edge was located poleward of $30^{\circ} \mathrm{S}$ and between $90^{\circ}$ and $70^{\circ} \mathrm{W}$ ). From these 166 days, 65 were associated with LOW25 days and 56 were associated with HIGH25 days.

The subgroup of 65 LOW25 days was associated with 58 unique cutoff lows (LOW25 cutoff lows), and the subgroup of $56 \mathrm{HIGH} 25$ days was associated with 41 unique cutoff lows (HIGH25 cutoff lows). The difference between the number of days and number of associated cutoff lows for each category was because a single cutoff low might be associated with more than one day of precipitation and because a single cutoff low could belong to both categories simultaneously. The nonunique categorization of a cutoff low occurred when, during the same day, a subgroup of rainfall stations measured low precipitation while another subgroup measured high precipitation, a feature that is favored by the complex terrain in central Chile (Falvey and Garreaud 2007; Barrett et al. 2009; Garreaud et al. 2016) and by mesoscale variability in the precipitation distribution of cutoff lows (Nieto et al. 2008). This nonunique categorization of the events was the case for five cutoff lows within our dataset, which were removed from the analyses to retain independence between both categories.

The spatial distribution of LOW25 and HIGH25 cutoff lows (Fig. 3) shows that both types of events were detected for the first time as they approached the western coast of South America, especially within the region $\left(25^{\circ}-50^{\circ} \mathrm{S}, 100^{\circ}-70^{\circ} \mathrm{W}\right)$, with LOW25 cutoff lows clustering equatorward and eastward of HIGH25 cutoff lows (Fig. 3a). In general, both types of events reached their minimum geopotential height near their position of first detection, with LOW25 cutoff lows being more likely to intensify after crossing the Andes cordillera (Fig. 3b). 
(a) Position of cut-off low at first detection



(b) Position of cut-off low at minimum geopotential height

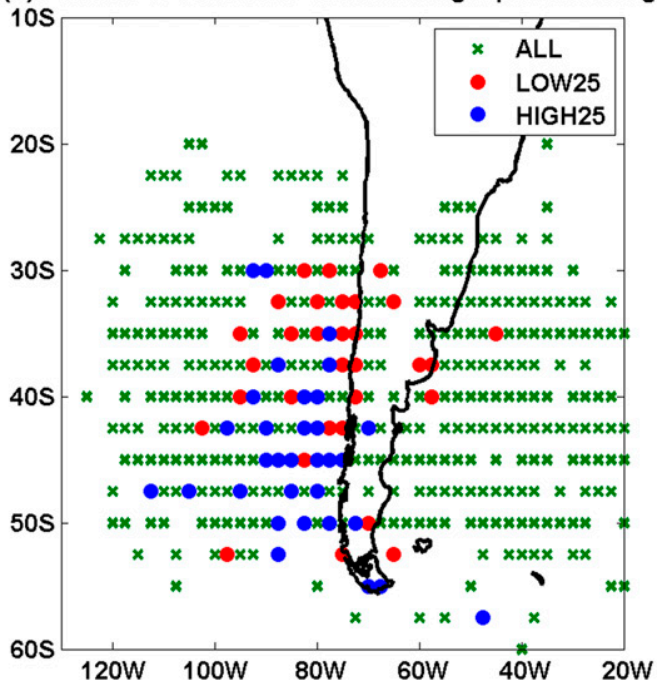

FIG. 3. Position of the 991 cutoff lows detected across South America during 1979-2017, and the position of LOW25 and HIGH25 cutoff lows. The positions are represented for the time of (a) first detection of the upper-level low and (b) geopotential height minimum.

Because cutoff lows tend to be slowly moving features (Fuenzalida et al. 2005), the clustering of LOW25 events equatorward of $\mathrm{HIGH} 25$ cutoff lows was also present when analyzing the trajectory of LOW25 and HIGH25 cutoff lows (Fig. 4). Especially during their first couple of days, LOW25 events tended to travel close to the western coast of South America between $30^{\circ}$ and $45^{\circ} \mathrm{S}$ (Fig. 4a), whereas HIGH25 events were more prone to distribute poleward of $40^{\circ} \mathrm{S}$ and off the western coast of South America (Fig. 4b). By locating farther from the Andes foothills than LOW25 events, HIGH25 events were more likely to reorganize the flow downstream and allow the development of a low-level low that could enhance orographic precipitation when this low-level low arrived at the continent. However, this hypothesis of orographic precipitation enhancement by the arrival of low-level low needs to be tested by a mesoscale modeling study.

When compared with HIGH25 systems, LOW25 systems were more likely to cross the Andes equatorward of $40^{\circ} \mathrm{S}$, even though that is where the Andes are higher, a result that may explain why LOW25 events were more persistent than HIGH25


FIG. 4. Trajectory of (a) LOW25 and (b) HIGH25 cutoff lows after a three-point average smoothing. Each color represents the trajectory of each system belonging to each group. The red-outlined areas represent the region where the trajectories of LOW25 or HIGH25 events tend to cluster. 


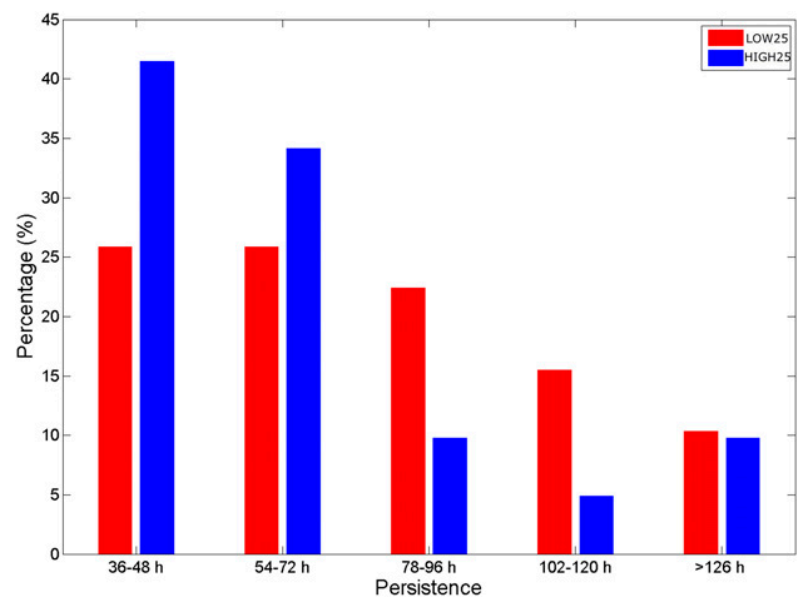

FIG. 5. Distribution of the persistence of LOW25 and HIGH25 cutoff lows, expressed as the percentage of cutoff lows that persisted for a given time interval.

events. Specifically, $48 \%$ of the LOW 25 systems persisted for longer than $72 \mathrm{~h}$, whereas only $25 \%$ of HIGH 25 cutoff lows did, with nearly $10 \%$ of both systems persisting for longer than 5 days (Fig. 5). Considering that nearly $70 \%$ of 500 -hPa cutoff lows persisted for less than $72 \mathrm{~h}$ in the regions of most frequent cutoff-low occurrence (Muñoz et al. 2020, their Fig. 11), the longer persistence of LOW25 events is a result that deserves further exploration. One hypothesis that could explain the diminished persistence in HIGH25 events is the downstream development of upper- and lower-tropospheric cyclones with a lower-tropospheric plume of water vapor under the influence of the strong high-level subtropical jet. These plumes are a source for latent heat release, one of the main mechanisms by which cutoff lows tend to dissipate (Hoskins et al. 1985). An alternative hypothesis for more persistent LOW25 events is the continuous injection of fresh polar air into LOW25 systems, as is the case for cutoff lows poleward of $50^{\circ} \mathrm{N}$ (Price and Vaughan 1992). However, LOW25 cutoff lows affecting central Chile usually occurred equatorward of $50^{\circ} \mathrm{S}$ (Fig. 4a). Thus, we hypothesize that the trajectory of cutoff-low systems is important for the upperlevel low's persistence.

Indeed, a quantitative analysis of the trajectories of LOW25 and HIGH25 cutoff lows relative to their final position, determined as the longitude and latitude corresponding to the last time step on which a grid point was considered to be part of a cutoff low (Figs. 6a,b), suggests around a third of the lifetime of LOW25 events was spent equatorward of their final


FIG. 6. (a) Average position (dots) and trajectory (solid lines) for each of the 58 LOW25 cutoff lows. Each average position is computed as the average latitude and average longitude of all cutoff-low grid points for a specific time step during the low's lifetime. For each LOW25 event (colors), the position is determined relative to the final position of the system, marked as the intersection of the red dashed lines. (b) As in (a), but for the 41 HIGH 25 cutoff lows. (c) Average position of LOW25 and HIGH25 cutoff lows, expressed as the percentage of time steps for which the low was found in each cardinal point with respect to the low's final position (FP). 

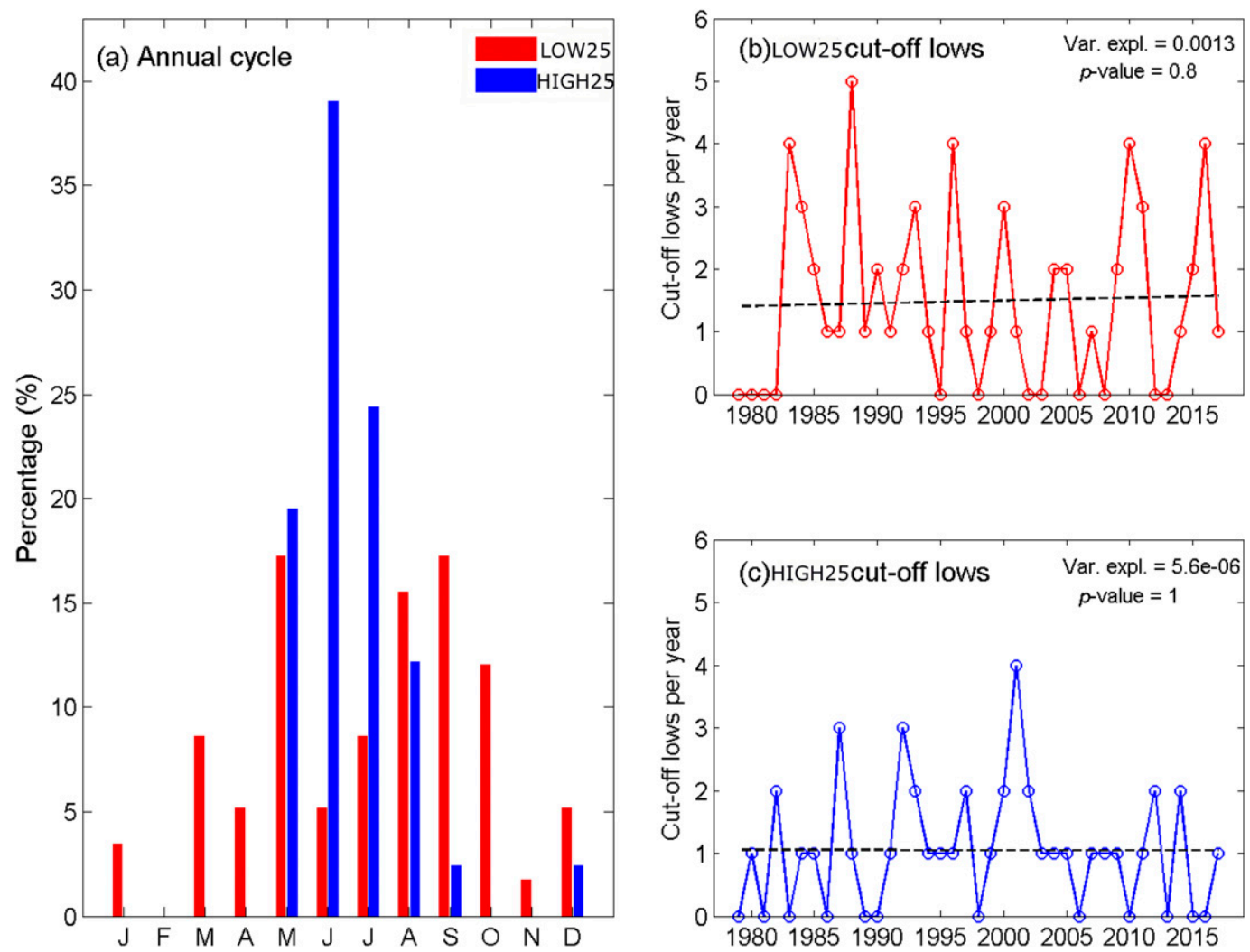

FIG. 7. (a) Annual cycle of LOW 25 and HIGH25 cutoff lows affecting central Chile, expressed as the percentage of events occurring during each month. Also shown is the interannual variability of (b) LOW25 and (c) HIGH25 cutoff lows, with the dashed black line indicating the linear regression line fitted to every time series. Indicated in (b) and (c) are the fraction of the variance of each time series explained by each linear regression ("Var. expl.") and the corresponding $p$ value of the two-sample $F$ test. With $p$ values this large, the interannual variation in the number of LOW25 or HIGH25 cutoff lows is not associated with any linear trend.

position (Fig. 6c). In contrast, for $\mathrm{HIGH} 25$ events the amount of time spent equatorward of their final position represented no more than $10 \%$ of their lifetime (Fig. 6c). The relatively short amount of time with respect to the lifetime of LOW25 and HIGH25 events in which the event moved equatorward of its final position is consistent with the polar origin and slow-moving cutoff lows. We hypothesize that the deeper equatorward excursion of LOW25 cutoff lows delayed their reabsorption by the main westerlies (hence, LOW25 events were more persistent), provided that the latent heat release around the LOW25 system was not as efficient as in the HIGH25 system to destroy the upper-level low before being reabsorbed.

With regard to their annual cycles, LOW25 and HIGH25 cutoff lows were most frequent during the rainy season in austral winter (May-September) and least frequent in austral summer (Fig. 7a). These results are consistent with the expected seasonality of 500-hPa cutoff lows in South America (Fuenzalida et al. 2005; Reboita et al. 2010; Pinheiro et al. 2017; Muñoz et al. 2020) and the seasonality of precipitation in central Chile (Falvey and Garreaud 2007).

LOW25 and HIGH25 cutoff lows in central Chile were infrequent. From the 39 years analyzed, there were less than two
LOW25 events per year in 30 of those years, and less than two HIGH25 events per year in 36 of those years. In some years, however, LOW25 or HIGH25 cutoff lows were as frequent as four or five events per year (Figs. 7b,c). Despite there being a positive trend in the number of 500-hPa cutoff lows per year in South America (Muñoz et al. 2020, their Fig. 15b), there was no statistically significant trend at the $95 \%$ level in the annual number of LOW25 or HIGH25 cutoff lows (Figs. 7b,c), according to an $F$ test applied to the linear regression model fitted to the annual number of LOW25 and HIGH25 cutoff lows. Note that the cutoff low associated with the early autumn 2015 high-impact precipitation event described in Bozkurt et al. (2016) was not included in our study (hence, the lack of HIGH25 events in 2015) because that cutoff low isolated from the main circulation at around $28^{\circ} \mathrm{S}$ (Bozkurt et al. 2016, their Fig. 5), equatorward of our study region defined earlier in this section.

Because both LOW25 and HIGH25 cutoff lows were most frequent during the rainy season, and because LOW25 events tended to be more persistent than HIGH25 events, the difference in the precipitation associated with LOW25 and HIGH25 cutoff lows was not associated with either seasonality or duration of the events. For this reason, we analyzed the 


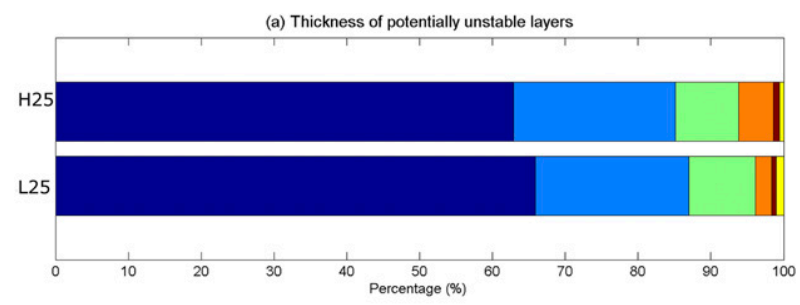

(b) Lifting needed to release instability

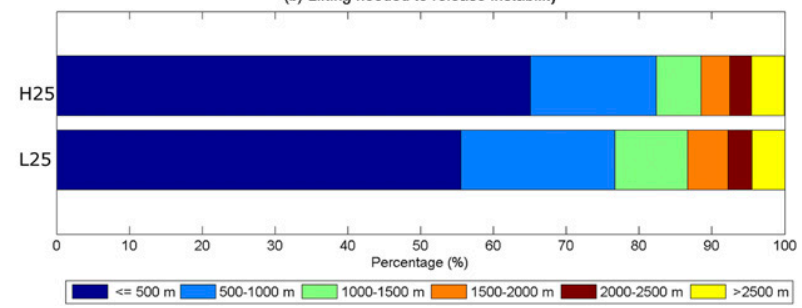

FIG. 8. (a) Distribution of the thickness of all potentially unstable layers found below $500 \mathrm{hPa}$ during LOW25 (L25) and HIGH25 (H25) days. (b) Distribution of the lifting necessary for potentially unstable layers to release the instability, calculated for LOW 25 (L25) and HIGH25 (H25) days.

three ingredients of deep moist convection separately for each kind of cutoff low.

\section{The role of instability, lift, and moisture in the development of LOW25 and HIGH25 cutoff lows}

\section{a. Thermodynamic instability}

Cutoff lows usually favor deep moist convection when they reach the warmer midlatitudes (Nieto et al. 2008). Deep moist convection, however, will only occur if three ingredients are in place: instability, lift, and moisture (McNulty 1978; Doswell 1987; Johns and Doswell 1992; McNulty 1995; Doswell et al. 1996). We consider two kinds of instability. The first is potential or convective instability, which is when the equivalent potential temperature decreases with height over a layer of the atmosphere (Rossby 1932; Schultz et al. 2000). This instability is released through layer lifting, such as over terrain. The second is conditional instability, which is when the environmental lapse rate lies between the moist and dry adiabatic lapse rates. Release occurs when a hypothetical air parcel ascends beyond its level of free convection.

We first examine potential instability. Potential instability existed in at least one layer below the 500-hPa level of every sounding analyzed, with a thickness that is less than $1000 \mathrm{~m}$ in nearly $85 \%$ of the cases (Fig. 8a). For quantifying how much lifting is needed for releasing the instability, we considered the air parcel with the highest relative humidity within each of these layers and computed its lifting condensation level following Eq. (22) in Romps (2017). In general, a lifting of $1500 \mathrm{~m}$ was sufficient for releasing the instability (Fig. 8b).

Next, we examined whether the zonal wind impinging on the Andes cordillera was strong enough to overcome the orographic blocking and lift the air parcels high enough to release the instability. To test how blocked the impinging westerly flow
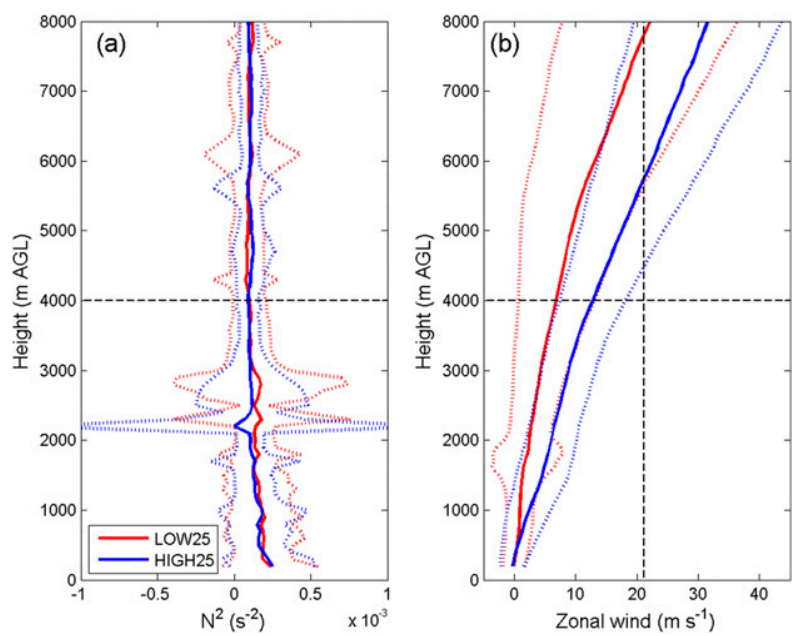

FIG. 9. Vertical profile of (a) the squared Brunt-Väisälä frequency and (b) the zonal wind during LOW25 and HIGH25 days. For each case, the solid contours represent the mean vertical profile and the dotted lines represent \pm 1 standard deviation from the mean. The dashed horizontal line represents the average height of the Andes cordillera in central Chile, and in (b) the vertical dashed line is the zonal wind speed necessary for a potentially unstable layer to release its instability by orographic lifting, assuming average conditions of Brunt-Väisälä frequency and a barrier height of $1500 \mathrm{~m}$, the upper limit of the height at which potentially unstable layers must ascend to release their instability.

was, we computed the Froude number, defined as $U /(N h)$, where $U$ is the zonal wind speed impinging on the Andes cordillera, $N$ is the Brunt-Väisälä frequency, and $h$ is the barrier height. Because the air parcels needed to be lifted less than $1500 \mathrm{~m}$ to release the instability, we set $h$ as the upper limit (1500 m) while the value of $N$ was calculated depending on the degree of saturation of the ascending air parcel. For air parcels with a relative humidity of less than $90 \%$, we used the dry Brunt-Väisälä frequency, whereas for air parcels with a relative humidity greater or equal to $90 \%$, we used the moist Brunt-Väisälä frequency. Following Barrett et al. (2011), we used a $90 \%$ threshold for relative humidity because moderate variations of relative humidity between $85 \%$ and $95 \%$ have little impact, if any, in the buoyancy frequency (Hughes et al. 2009). The dry Brunt-Väisälä frequency $N_{d}$ and the moist Brunt-Väisälä frequency $N_{m}$ were computed as

$$
\begin{aligned}
& N_{d}^{2}=g \frac{\partial \ln \theta_{v}}{\partial z} \text { and } \\
& N_{m}^{2}=\frac{g}{T}\left(\frac{\partial T}{\partial z}+\Gamma_{m}\right)\left(1+\frac{L q_{s}}{R T}\right)-\frac{g}{1+q} \frac{\partial q}{\partial z},
\end{aligned}
$$

where $g$ is the gravitational acceleration, $\theta_{v}$ is the virtual potential temperature, $T$ is the air temperature, $\Gamma_{m}$ is the moist adiabatic lapse rate, $L$ is the latent heat of vaporization, $q$ is the water-vapor mixing ratio, and $R$ is the gas constant for dry air.

The five-point smoothed vertical profile of average $N^{2}$ showed little difference between LOW25 and HIGH25 days (Fig. 9a), with an average $N^{2}$ of around $2 \times 10^{-4} \mathrm{~s}^{-2}$ below the 


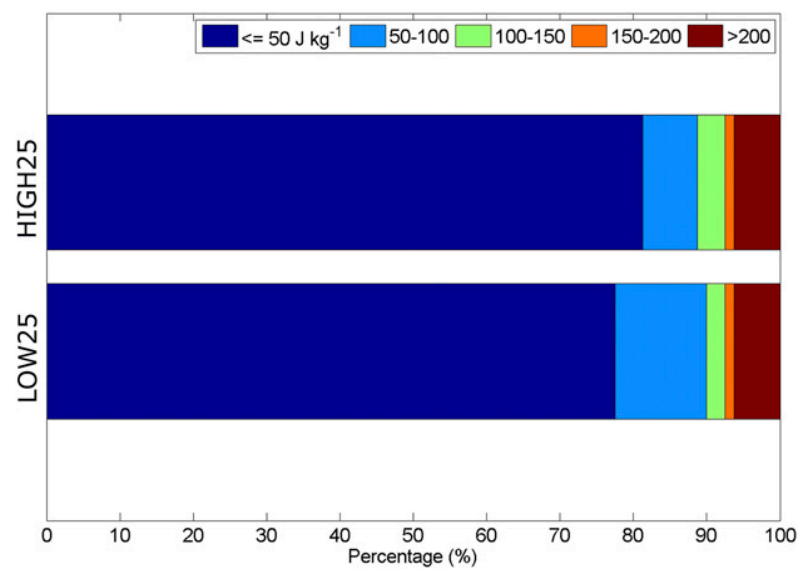

FIG. 10. Distribution of the values of the most unstable CAPE attained during LOW25 and HIGH25 days.

first $3 \mathrm{~km}$. Considering the maximum of $1500-\mathrm{m}$ lifting that the air parcel must undergo to release the instability, we calculated that an air parcel subject to a squared buoyancy frequency of $2 \times 10^{-4} \mathrm{~s}^{-2}$ needed a zonal wind speed of at least $21.2 \mathrm{~m} \mathrm{~s}^{-1}$ to release the instability by orographic lifting alone (when $U=$ Nh). A zonal wind this large was usually not found at levels below the Andes cordillera (Fig. 9b), so orographic lifting was unlikely to release the instability from potentially unstable layers in general.

We next examined conditional instability by analyzing CAPE. However, CAPE values were equal to zero in around $80 \%$ of all available soundings, with the remaining $20 \%$ having a CAPE value that was usually below $35 \mathrm{~J} \mathrm{~kg}^{-1}$, barely enough to produce lightning in the mixed-phase region of a cloud (van den Broeke et al. 2005). Values of CAPE this low were a consequence of choosing air parcels from the lowest $500 \mathrm{~m}$ (where the air was mostly stable due to the presence of the cool southeastern Pacific Ocean) to compute CAPE. Nonetheless, low values of CAPE were attained even considering the most unstable CAPE from each sounding, which in nearly $90 \%$ of the cases had a value below $100 \mathrm{~J} \mathrm{~kg}^{-1}$ regardless of the kind of day (LOW25 or HIGH25) considered (Fig. 10). Thus, the difference in precipitation between LOW25 and HIGH25 days likely depended on the strength of the synoptic-scale ascent necessary to release the instability and on the moisture input at the leading edge of cutoff lows and not on the degree of instability.

\section{b. Lift}

Because no direct measurements of vertical motion were available, we calculated the synoptic-scale ascent and descent around LOW25 and HIGH25 cutoff lows by computing the 500-hPa convergence of the $\mathbf{Q}$ vector (Holton 2004, his section 6.4.2). As expected, when the upper-level low reached its minimum in geopotential height, the LOW25 and HIGH25 composites showed synoptic-scale ascent at the leading edge of the systems while synoptic-scale descent was dominant at the western flank, consistent with the regions of warm-air advection and cold-air advection around Southern Hemisphere upper-level lows (Figs. 11a,b). A two-sample Student's $t$ test showed that the stronger synoptic-scale ascent at the leading edge and the synoptic-scale descent at the western flank of LOW25 systems were not different at the $95 \%$ level from the patterns obtained for HIGH25 systems.

Even so, to check how different the three-dimensional patterns for ascent and descent were in LOW25 and HIGH25 systems, we used the omega field from the NCEP-NCAR reanalysis for building a vertical profile of omega along a transect from the leading edge to the polar and western border (herein "trailing edge") of cutoff-low systems. The vertical profile of omega was consistent with the 500-hPa Q-vector convergence. Specifically, the ascent at the leading edge of LOW25 events was more intense than for $\mathrm{HIGH} 25$ events, especially above $750 \mathrm{hPa}$ (Fig. 11c), and descent dominated at the trailing edge, with LOW25 events having a broader and stronger area of descent within the 850-700-hPa layer than HIGH25 events (Fig. 11d). Following a two-sample Student's $t$ test, the difference in the average descent at the trailing edge was statistically significant at the $95 \%$ level throughout the air column, especially within $500 \mathrm{~km}$ from the cutoff-low center.

The physical mechanism explaining the patterns for vertical motion in LOW25 and HIGH25 events can be determined from Q-vector partitioning under a natural coordinate system that follows the isohypses of the 500-hPa isobaric surface (Jusem and Atlas 1998). In such a coordinate system, $\mathbf{t}$ and $\mathbf{n}$ are the unit vectors for the natural coordinates $(s, n)$ parallel to and normal to the geostrophic wind, respectively, with $\mathbf{n}$ oriented so that it is positive when pointing to the left of the flow. Jusem and Atlas (1998) showed that $\mathbf{Q}$ can be written in the following form:

$\mathbf{Q}=-\mathbf{t} \frac{R}{p}\left(\frac{\partial s_{g}}{\partial s} \frac{\partial T}{\partial s}+K_{s} s_{g} \frac{\partial T}{\partial n}\right)-\mathbf{n} \frac{R}{p}\left(\frac{\partial s_{g}}{\partial n} \frac{\partial T}{\partial s}+K_{n} s_{g} \frac{\partial T}{\partial n}\right)$,

where $s_{g}$ is the geostrophic wind speed, $K_{s}$ is the curvature of the isohypses (negative for clockwise rotation and positive for counterclockwise rotation), and $K_{n}$ is the curvature of the lines normal to the isohypses (negative for confluence and positive for diffluence). This partitioning of the vertical motion produces the four terms on the right-hand side of the equation: along-stream deformation of isohypses (Fig. 12a), curvature of isohypses (Fig. 12b), temperature advection by horizontal wind shear (Fig. 12c), and cross-stream deformation of isohypses (Fig. 12d). By computing the forcing of quasigeostrophic omega $(-2 \nabla \cdot \mathbf{Q})$ associated with each of these four forcings, along-stream deformation of the isohypses and temperature advection by horizontal wind shear produced weak vertical motions in both LOW25 and HIGH25 (Figs. 13a,b,e,f). Thus, the main mechanisms by which ascent at the leading edge and descent at the polar western edge of cutoff lows occurred were associated with curvature of the geostrophic flow and crossstream deformation of isohypses (Figs. 13c,d,g,h). Although the vertical motions associated with curvature showed a similar pattern between LOW25 and HIGH25 cutoff lows, the vertical motions were stronger in LOW25 cutoff lows. This stronger vertical motion, when combined with the pattern obtained for cross-stream deformation, explains the stronger ascent at the leading edge and the stronger descent at the polar western edge of LOW25 cutoff lows (Figs. 11a,c). 
(a) Q-vector convergence and H500 (LOW25)



(c) Vertical profile of omega (LOW25)

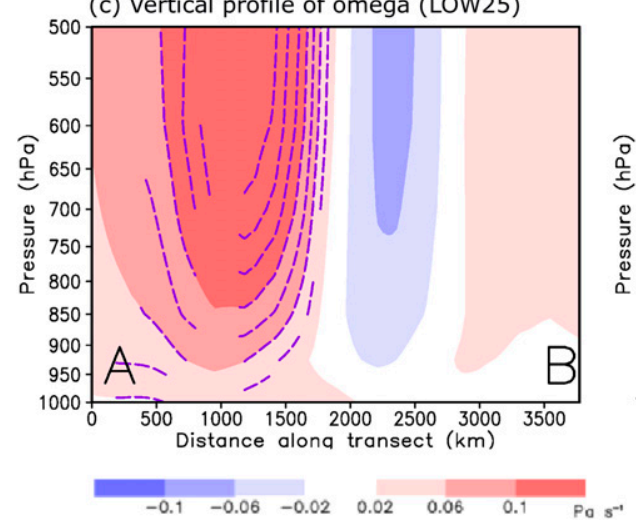

(b) Q-vector convergence and $\mathrm{H} 500$ ( $\mathrm{HIGH} 25)$



$\begin{array}{lllllllllllll}-12 & -9 & -6 & -3 & 3 & 6 & 9 & 12 & * 1 \mathrm{e}-19 & \mathrm{~m} \mathrm{~s}^{-1} & \mathrm{~kg}^{-1}\end{array}$ (d) Vertical profile of omega (HIGH25)

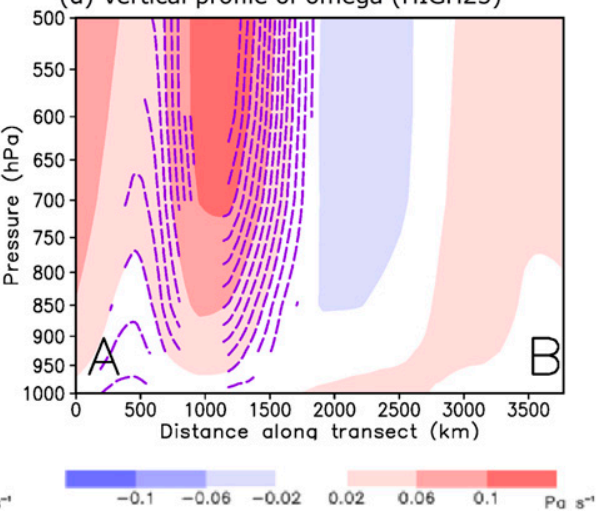

FIG. 11. (a) Composite of the 500-hPa spatial distribution of the quasigeostrophic forcing for vertical velocity $(-2 \nabla \cdot \mathbf{Q}$; shaded) and geopotential height (dam; contours) around (a) LOW25 and (b) HIGH25 cutoff lows. The spatial distribution is relative to the center of the upper-level low when the geopotential height there is minimum. Also shown is the vertical profile of the vertical velocity $(\omega=d p / d t)$ along the western polar edge and leading edge of (c) LOW25 and (d) HIGH25 cutoff lows [transect AB in (a) or (b), respectively]. For every panel, purple dashed grid points indicate points where the difference between LOW25 and HIGH25 cutoff lows is statistically significant at the $95 \%$ level. For (a) and (b), positive values of $-2 \nabla \cdot \mathbf{Q}$ are associated with ascent, and negative values are associated with descent. For (c) and (d), the distance between A and B was computed considering two points that define the southwest corner and northeast corner of a region encompassing the subtropical western coast of South America and the southeast Pacific Ocean, the region where cutoff lows affecting central Chile are found. Point A is located at $\left(50^{\circ} \mathrm{S}, 90^{\circ} \mathrm{W}\right)$, and point $\mathrm{B}$ is located at $\left(20^{\circ} \mathrm{S}, 70^{\circ} \mathrm{W}\right)$.

Therefore, the seemingly stronger ascent at the leading edge of LOW25 cutoff lows was driven mostly by the ascent associated with curvature of the geostrophic flow and cross-stream deformation of isohypses. Studying the influence of these mechanisms on the precipitation totals associated with cutoff lows is beyond the scope of this article, but the similarity of the spatial patterns and the intensity of vertical motion associated with the rest of the forcings analyzed suggests the strength of the ascent, just like the instability from section $4 \mathrm{a}$, was not the key ingredient that differentiated LOW25 from HIGH25 events.

\section{c. Moisture}

Given that CAPE values and the ascent at the leading edge were fairly similar between LOW25 and HIGH25 systems, we hypothesize that $\mathrm{HIGH} 25$ cutoff lows were associated with a larger precipitation amount than LOW25 cutoff lows because of different moisture distributions around the upper-level lows. As cutoff lows have a moist area at the leading edge and a dry area behind (M1 and D1 in Fig. 2), we checked the IVT distribution around LOW25 and HIGH25 cutoff lows to evaluate whether the merging of any external moisture plume with the moist area could increase the precipitation associated with cutoff lows.

Indeed, the spatial distribution of IVT around LOW25 cutoff lows showed an elongated area with intense water-vapor transport (or moisture plume) mostly located poleward and westward of the upper-level low, whereas moderate values of water-vapor transport existed at the leading edge of the system (Figs. 14a-d). This asymmetric water-vapor distribution persisted from the formation of the parent trough (Fig. 14a) to the demise of the upper-level system (Fig. 14d) and was a consequence of a stronger polar branch of the westerlies poleward of the cutoff low (Figs. 14b,c). As discussed in section 3a, the moisture plume westward and poleward of LOW25 cutoff lows might be associated with the passage of cold fronts following the arrival of cutoff lows. Were this moisture plume to arrive at 

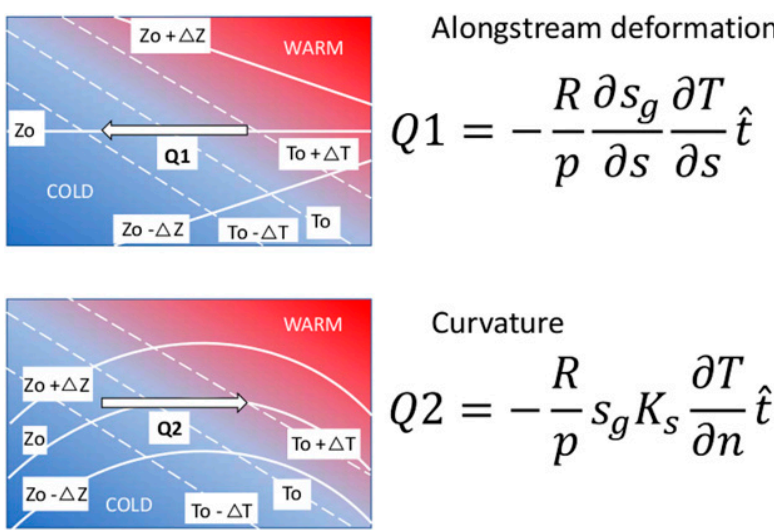

$$
\begin{aligned}
& \text { Curvature } \\
& Q 2=-\frac{R}{p} s_{g} K_{s} \frac{\partial T}{\partial n} \hat{t}
\end{aligned}
$$

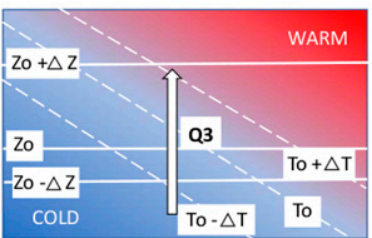

Temperature advection by horizontal wind shear

$$
Q 3=-\frac{R}{p} \frac{\partial s_{g}}{\partial n} \frac{\partial T}{\partial s} \hat{n}
$$

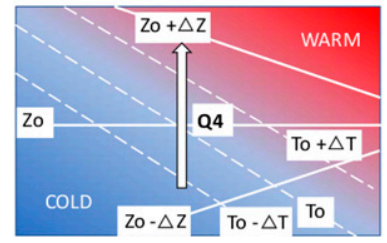

Cross-stream deformation

$$
Q 4=-\frac{R}{p} s_{g} K_{n} \frac{\partial T}{\partial n} \hat{n}
$$

FIG. 12. Schematic representation of each of the four terms of the Q vector for a natural coordinate system that follows the geostrophic wind. For every panel, red shading represents warm areas and blue shading represents cold areas. White solid lines represent geopotential height contours $\left(Z_{0}-\Delta Z, Z_{0}\right.$, and $\left.Z_{0}+\Delta Z\right)$, white dashed lines represent temperature contours $\left(T_{0}-\Delta T, T_{0}\right.$, and $\left.T_{0}+\Delta T\right)$, and the arrow represents the direction for the corresponding $\mathbf{Q}$-vector component. Along with each schematic, the $\mathbf{Q}$-vector expression for each component is displayed.

central Chile and the cyclonic circulation associated with the 500-hPa cutoff low to extend to lower levels and persist until then, the easterly wind at the polar edge of the cutoff low may weaken the intensity of the arriving plume, thereby favoring the drier conditions in central Chile.

In contrast, when compared with the average South American cutoff low (Fig. 2), the leading edge of HIGH25 cutoff lows featured above-average water-vapor transport toward the continent (Figs. 14e-h), consistent with the case study in northern Chile documented by Bozkurt et al. (2016) and with the penetration of a narrow plume of moist air typical of precipitating cutoff lows in Iraq (Al-Nassar et al. 2020). This higher watervapor transport was favored because moisture was mostly transported by the equatorial branch of the split westerlies (whose magnitude was similar to the LOW25 composite) and not by the polar branch (whose magnitude was much weaker in the HIGH25 composite) as for LOW25 cutoff lows. This additional moisture at the leading edge of HIGH25 cutoff lows usually comes from moisture plumes affecting Chile, which have a marked seasonality. Specifically, these moisture plumes arrive at central Chile most frequently during winter (Viale et al. 2018), consistent with the increased frequency of HIGH25 cutoff lows during the rainy season (Fig. 7a).

The arrival of moisture plumes to the leading edge of cutoff lows and central Chile is important because these plumes are a source for latent heat release by water-vapor condensation windward of the Andes (Viale et al. 2018). Because latent heat release is one of the main mechanisms for the decay of cutoff lows (Hoskins et al. 1985), the shorter persistence of HIGH25 cutoff lows with respect to LOW25 cutoff lows could not only be due to a closer positioning of HIGH25 systems to the main westerlies (as discussed in section 3b), but also to the presence of a moisture plume near the leading edge of $\mathrm{HIGH} 25$ cutoff lows.

Further analysis of the water-vapor transport at the leading edge of cutoff lows confirms less moisture input in LOW25 cutoff lows compared to HIGH25 cutoff lows, especially during the formation stage of the system (Figs. 15a,b). Specifically, up to $24 \mathrm{~h}$ before the cutoff-low center reached its minimum geopotential height, the average IVT at the leading edge was above $200 \mathrm{~kg} \mathrm{~m}^{-1} \mathrm{~s}^{-1}$ in about $20 \%$ of LOW 25 cutoff lows and in about $40 \%$ of HIGH25 cutoff lows (Figs. 15a,b). After the $500-\mathrm{hPa}$ geopotential height at the cutoff-low center reached its minimum (Fig. 15c), the differences in the IVT at the leading edge of the LOW25 and HIGH25 systems tended to be similar during the later stages (Figs. 15d-f). As the differences in IVT at the leading edge of cutoff lows were more obvious during earlier stages, extreme-precipitation days in central Chile associated with cutoff lows were more likely to occur around the genesis and intensification stages and not during the weakening stage of cutoff lows.

\section{Case studies of LOW25 and HIGH25 cutoff lows}

Extreme-precipitation days in central Chile associated with cutoff lows, therefore, depend on the positioning of the upperlevel low with respect to any preexisting moisture plume. Specifically, stronger moisture plumes occurring equatorward of the cutoff low are more likely to be associated with heavy precipitation when these plumes arrive to the leading edge of the system and the southwestern coast of South America. To illustrate this dependence, let us consider two cutoff lows affecting central Chile that were independent of each other: one identified as a LOW 25 cutoff low that left an average precipitation of around $4 \mathrm{~mm}$ per station during the heaviest precipitation day associated with the LOW25 cutoff low, and the other identified as a HIGH25 cutoff low that left an average precipitation of around $20 \mathrm{~mm}$ per station during the heaviest precipitation day associated with the HIGH25 cutoff low. These lows occurred during the rainy season (between 22 and 26 April 2004 for the LOW25 case and between 11 and 14 July 2001 for the HIGH25 case) and were selected because their geopotential height field and moisture distribution were consistent with the composites of Fig. 14 and also because the LOW25 system was more persistent than the HIGH25 system (102 h vs $78 \mathrm{~h}$ ), in agreement with Fig. 6.

The LOW25 cutoff low developed from the equatorward extrusion of a $500-\mathrm{hPa}$ short-wave trough over the western 
LOW25


Curvature


HIGH25
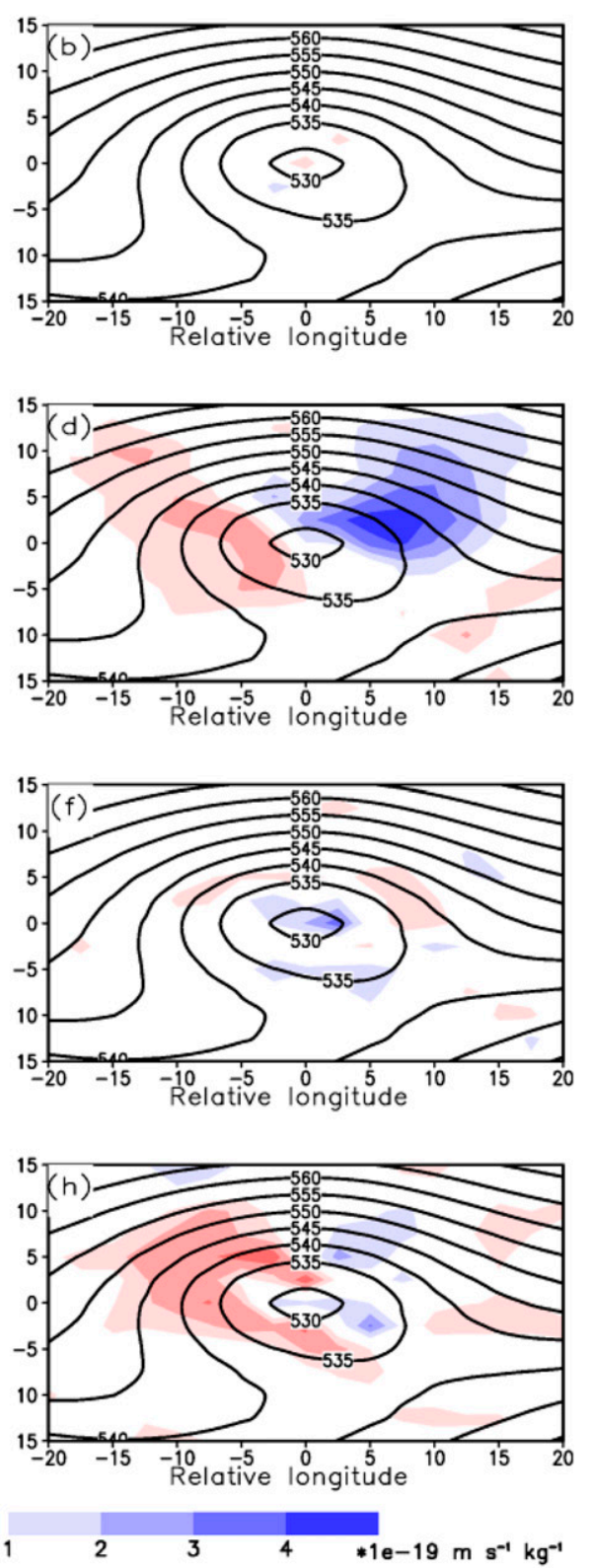

FIG. 13. Composite of the 500-hPa spatial distribution of geopotential height (dam; contours) and $-2 \nabla \cdot \mathbf{Q}$ (shaded), but for every quasigeostrophic forcing of vertical velocity at the time the geopotential height at the center of the (left) LOW25 and (right) HIGH25 cutoff low is minimum. There are four forcings of vertical velocity considered: (a),(b) along-stream deformation of the flow; (c),(d) curvature of the flow; (e),(f) temperature advection by horizontal wind shear; and $(\mathrm{g}),(\mathrm{h})$ cross-stream deformation. Positive values of $-2 \nabla \cdot \mathbf{Q}$ are associated with ascent, and negative values are associated with descent.

coast of South America. Before the formation of the cutoff low, there was a well-defined 500-hPa ridge west of the short-wave trough over the southeastern Pacific Ocean and also a closed high at around $\left(35^{\circ} \mathrm{S}, 100^{\circ} \mathrm{W}\right)$. The $850-\mathrm{hPa}$ moisture distribution featured a well-defined moisture plume at the west of the main axis of the ridge, a secondary moisture plume around the southeastern Pacific Ocean that came from the main moisture plume and turned cyclonically toward the western coast of
South America, and abundant moisture across the Amazon basin (Fig. 16a). As the ridge extended toward the southern tip of South America, the base of the trough isolated from the main westerlies and a cutoff low centered at about $\left(35^{\circ} \mathrm{S}, 70^{\circ} \mathrm{W}\right)$ developed (Fig. 16b), consistent with the positioning of LOW25 cutoff lows shown in Fig. 3. Further extension of the ridge toward the continent deformed the parent trough, such that its main axis became oriented almost zonally as the cutoff low 
LOW25
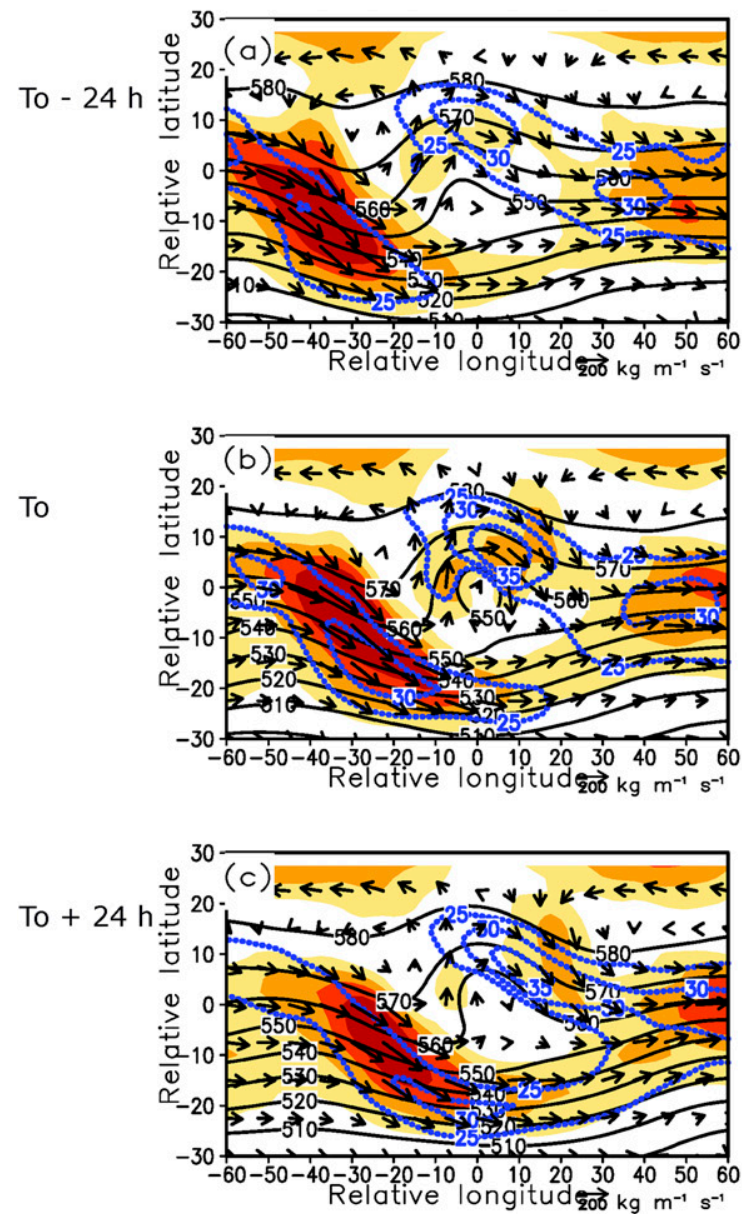

HIGH25
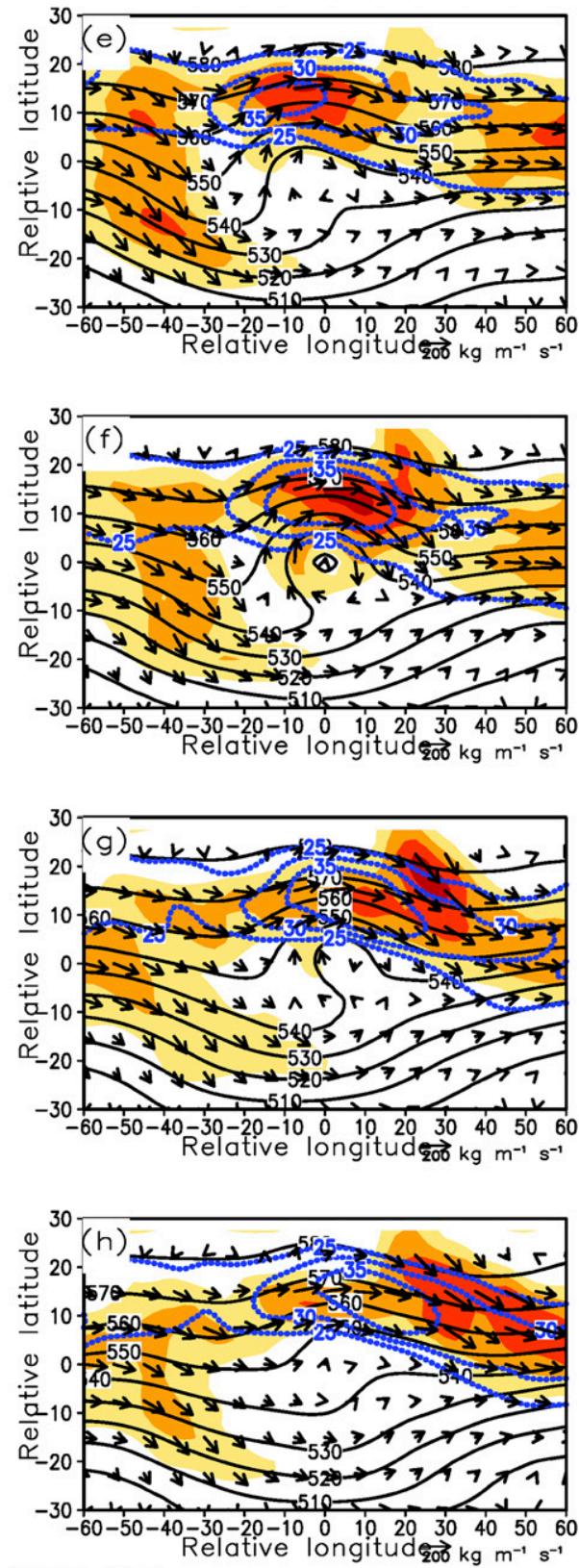

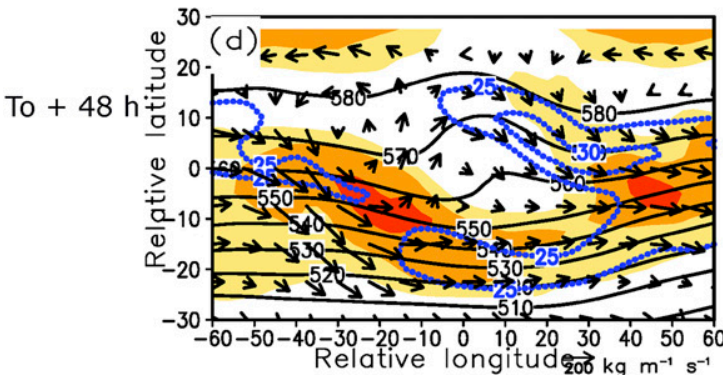

$100 \quad 150200250 \quad \mathrm{~kg} \mathrm{~m}^{-1} \mathrm{~s}^{-1}$

FIG. 14. Composites of the magnitude of IVT (shaded), direction of IVT (arrows), 300-hPa horizontal wind speed ( $\mathrm{m} \mathrm{s}^{-1}$; dotted blue contours), and 500-hPa geopotential height (dam; solid black contours) for (a)-(d) LOW25 and (e)-(h) HIGH25 cutoff lows. The composites are shown for the following times: (top) $24 \mathrm{~h}$ before the geopotential height is minimum at the center of the low, (top middle) at time $T_{0}$, when the geopotential height is minimum at the center of the low, and (bottom middle) 24 and (bottom) $48 \mathrm{~h}$ after reaching the minimum. In all panels, latitudes and longitudes are expressed relative to the low center at time $T_{0}$.

developed further, with moisture at the leading edge of the cutoff low mostly concentrated on the eastern side of South America (Fig. 16c).

Therefore, the moisture available for precipitation in central Chile for this case came from the secondary moisture plume and from the Amazon basin. However, the secondary plume had already weakened when the cutoff low formed, and the moisture advected from the Amazon basin remained mostly east of the Andes because of mechanical blocking (Garreaud and Fuenzalida 2007). Thus, less moisture may explain the 
(a) To-24h

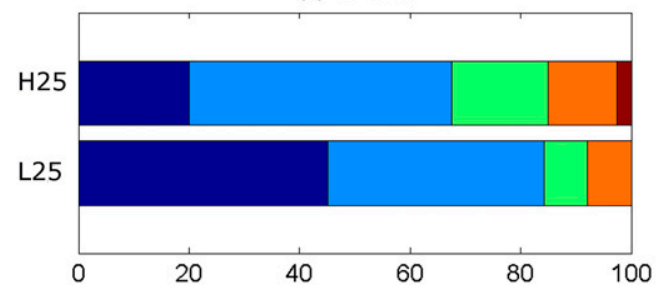

(c) To



(e) To+24h



(b) To-12h

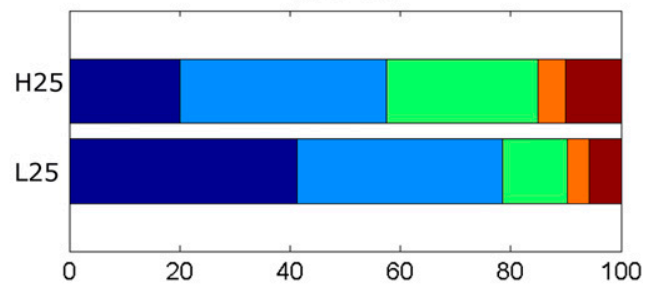

(d) To+12h

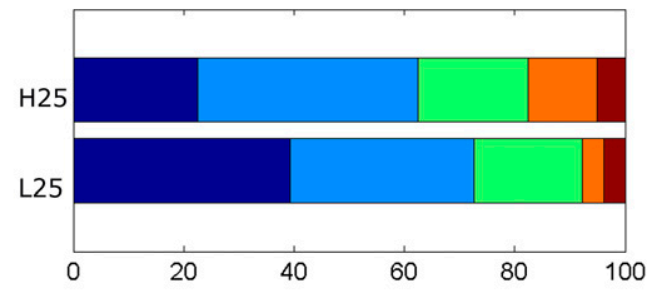

(f) To+48h

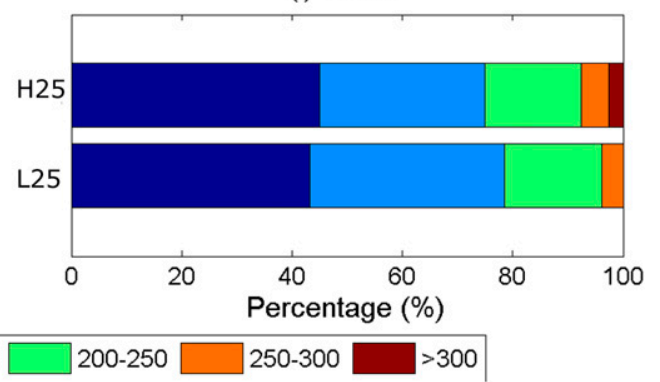

FIG. 15. Average IVT distribution at the leading edge of LOW25 (L25) and HIGH25 (H25) cutoff lows. Consistent with the region M1 in Fig. $2 \mathrm{~b}$, the leading edge is the region extending $20^{\circ}$ eastward and $20^{\circ}$ equatorward from each cutoff-low center. This average is computed for the following times: (a) 24 and (b) $12 \mathrm{~h}$ before the geopotential height is minimum at the center of the low, (c) at time $T_{0}$ when the geopotential height is minimum at the center of the low, and (d) 12 , (e) 24 , and (f) $48 \mathrm{~h}$ after reaching the minimum.

lesser amount of precipitation associated with this cutoff low. However, the orientation of the parent trough was also important in preventing the arrival of the primary moisture plume-specifically, the tilting of the main axis of the parent trough resulting in southeasterly wind and allowing the broadening of the polar tip of the arriving moisture plume. This broadening of the polar tip prevented the moisture plume from arriving focused within a narrow band to central Chile, a feature that would have enhanced the precipitation following the passage of the cutoff low. Thus, considering the tilting of the main axis of the trough is typical of Southern Hemisphere troughs (Reboita et al. 2010; Muñoz et al. 2020), the positioning where the cutoff low occurred was important for explaining the low precipitation associated with this LOW25 event.

A different mechanism occurred for the HIGH25 case, in which the main synoptic-scale feature prior to the occurrence of the cutoff low was a well-defined moisture plume equatorward of the parent trough (Fig. 16d). Unlike the LOW25 cutoff low, this upper-level low formed farther west at around $95^{\circ} \mathrm{W}$ (Fig. 16e), and because of its positioning with respect to the moisture plume, the development of heavy precipitation in central Chile was favored. Specifically, the moisture plume in this case was deflected toward the continent as it merged with the leading edge of the cutoff low (Figs. 16e,f). This deflection caused an increased moisture input toward central Chile and therefore an increased likelihood of a heavy-precipitation event there. Indeed, by comparing the average precipitation per station between both events, the HIGH25 event had around 5 times more average precipitation in the area than the LOW25 event. This simple comparison between the two types of events described in this article shows cutoff lows can have different impacts in terms of precipitation amount. They can either favor the moisture input toward the continent if the cutoff low forms poleward of a preexisting moisture plume or they can redirect the transport of moist air to the continent if the parent trough tilts westward. Of course, not all cutoff lows associated with extreme-precipitation events form with preexisting moisture plumes arriving at the low's leading edge, because the moisture necessary for convection can also be provided by a warm ocean in subtropical latitudes (Nieto et al. 2008).

\section{Conclusions}

We analyzed the influence that the geopotential height distribution, thermodynamic instability, lift, and moisture distribution 
LOW25

(a) 0600 UTC 21 April 2004

To - $24 \mathrm{~h}$

To

To $+24 h$

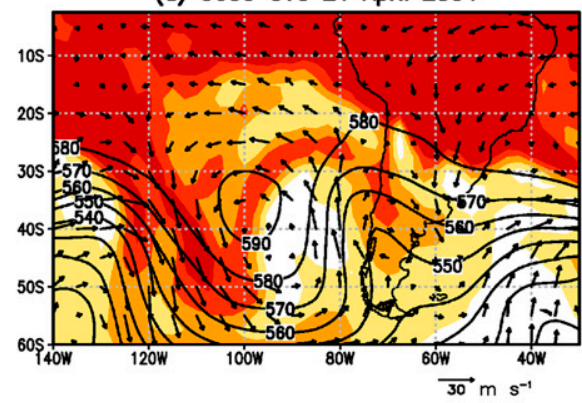

(b) 0600 UTC 22 April 2004

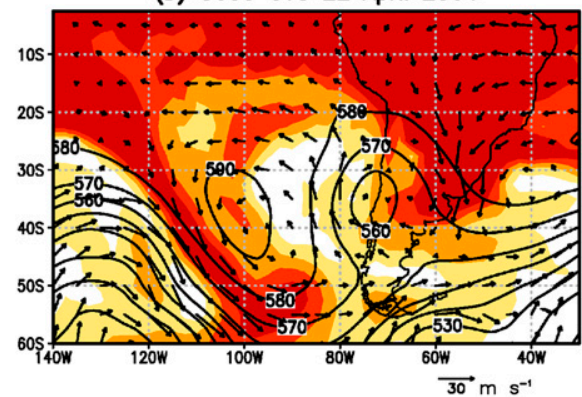

(c) 0600 UTC 23 April 2004

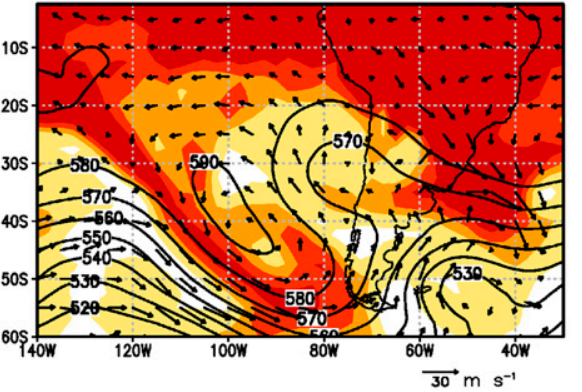

HIGH25

(d) 0600 UTC 11 July 2001

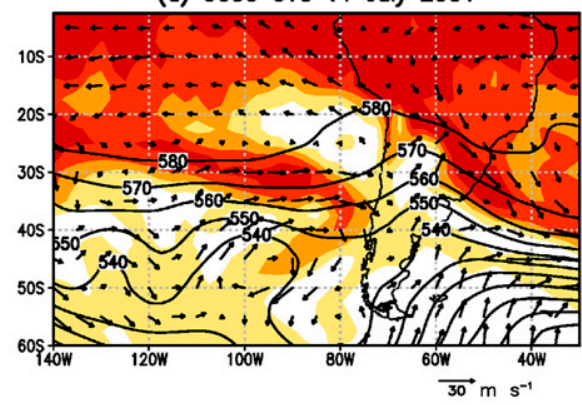

(e) 0600 UTC 12 July 2001

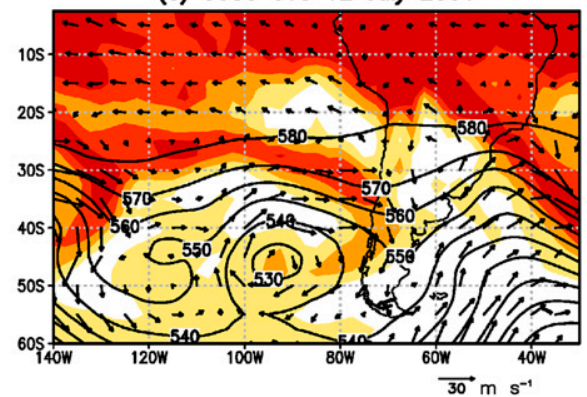

(f) 0600 UTC 13 July 2001

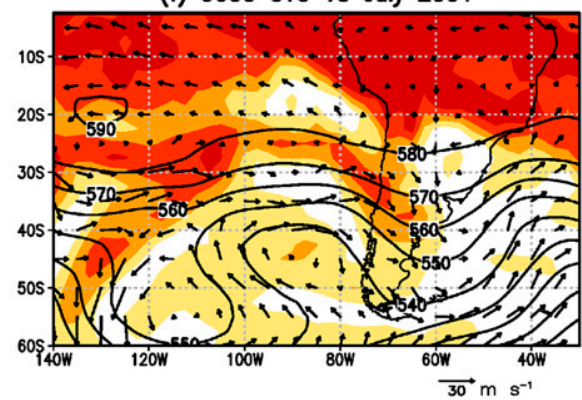

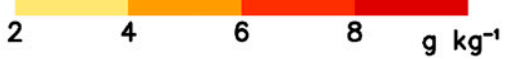

FIG. 16. Spatial distribution of 850-hPa water-vapor mixing ratio (shaded), 500-hPa geopotential height (dam; contours), and 850-hPa horizontal wind (arrows) around South America for three time steps: (top) $24 \mathrm{~h}$ before the first detection of a cutoff low $\left(T_{0}-24 \mathrm{~h}\right)$, (middle) at the time the cutoff low was first detected $\left(T_{0}\right)$, and (bottom) $24 \mathrm{~h}$ after the first detection $\left(T_{0}+24 \mathrm{~h}\right)$. Maps are displayed for two cases representing each category of cutoff low discussed: (a)-(c) a LOW25 cutoff low and (d)-(f) a HIGH25 cutoff low. The LOW25 cutoff low is studied between 21 and 23 Apr 2004, and the HIGH25 cutoff low is studied between 11 and 13 Jul 2001.

had in the amount of daily precipitation associated with 500-hPa cutoff lows in central Chile. The main findings of this article can be summarized as follows.

- On the synoptic scale, these cutoff lows had a moist and a dry area that were consistent with the integrated precipitablewater distribution around cutoff lows affecting southern Africa shown by Favre et al. (2012). Whereas the moist area was located at the low's leading edge, the dry area was located west of the low's center. West of the dry feature, there was a secondary moist area associated with a following cold front, which merged with the leading edge of the upper-level low as the cutoff low developed further. Because of veering of the geostrophic wind, the moist areas were located within areas of warm and moist air advection, and the backing of the geostrophic wind around the dry area suggests cold and dry air advection occurred there, consistent with the intrusion of upper-tropospheric and lower-stratospheric air into cutoff lows. In general, the area of influence of the leading edge of the cutoff low extended about $20^{\circ}$ eastward and $20^{\circ}$ equatorward of the upper-level low center. Thus, this area was used for defining whether a precipitation day in central Chile was associated with a 500-hPa cutoff low. 
- Despite both LOW25 and HIGH25 cutoff lows occurring most frequently during the rainy season (May to September), LOW25 cutoff lows were more persistent than HIGH25 cutoff lows. The difference in persistence probably arose because, during the cutoff low's lifetime, LOW25 events tended to be farther equatorward from the main westerlies than HIGH25 events, hence slowing the reabsorption into the main westerlies. Additional hypotheses for the shorter persistence of HIGH25 cutoff lows include the downstream development of upper- and lower-tropospheric cyclones under the influence of the strong subtropical jet and the positioning of a moisture plume around the leading edge of $\mathrm{HIGH} 25$ events because of the latent heat release associated with these moisture plumes when impinging on the windward side of the Andes. These hypotheses still need to be tested as an alternative hypothesis such as diabatic heating eroding the upper-level low has not been assessed from a climatological perspective.

- The synoptic-scale vertical motions around LOW25 and HIGH25 cutoff lows were associated primarily with curvature of the flow and with cross-stream deformation of isohypses. Both mechanisms, while important for allowing the ascent of moist air at the leading edge of cutoff lows, showed no statistically significant difference between LOW25 and HIGH25 events.

- Because the impinging westerly flow was mostly blocked by the Andes, instability release by orographic lifting was difficult. Thus, this instability release occurred mostly by synoptic-scale ascent at the leading edge of cutoff lows. Because this ascent was fairly similar between LOW25 and HIGH25 systems, the main difference in the amount of precipitation associated with LOW25 and HIGH25 systems was the moisture input at each leading edge. Indeed, the water-vapor transport to the leading edge of LOW25 cutoff lows was weaker than for HIGH25 cutoff lows. This weakened vapor transport might have been the reason for lower precipitation amounts in LOW25 events, which seems consistent with the weaker moisture plume at the upper-level low's leading edge in Fig. 16. A moisture budget, however, could confirm this hypothesis. As the cutoff low developed further and weakened, there was no difference in the moisture influx between LOW25 and HIGH25 events. Thus, extremeprecipitation events associated with cutoff lows were more likely to occur during early stages of the cutoff low. As cutoff lows usually persisted for around three days, it is key to improve nowcasting capabilities especially in areas where cutoff lows tend to initiate heavy-precipitation events. This improvement is particularly important in areas with complex terrain, where there is an increased risk of hazardous weather and consequent impacts such as landslides and flooding.

- Even though both LOW25 and HIGH25 cutoff lows have an equatorial moisture plume arriving at the upper-level low's leading edge, the equatorial moisture plume was on average more defined and stronger in HIGH25 cutoff lows. As a consequence, the amount of moisture available for precipitation associated with cutoff lows was larger for HIGH25 events. However, the case study showed the moisture at the leading edge may be large but mostly blocked by the
Andes, a feature that added to the westward tilting of the parent trough that broadened the polar tip of an incoming polar moisture plume, diminishing the precipitation in central Chile. Therefore, the positioning of the cutoff low with respect to the equatorial moisture plume was key for determining the precipitation regime associated with the upperlevel low.

The work presented here also provides evidence that the transport of moist air from the equatorial eastern Pacific Ocean to the western coast of South America by northwesterly wind equatorward of a cutoff low (as described for a case study by Bozkurt et al. 2016) can be generalized to other heavyprecipitation events in central Chile. This generalization could be extended to other regions where cutoff-low occurrence and the arrival of moisture plumes is frequent, such as western North America (Abatzoglou 2016), southern Africa (Blamey et al. 2018), and western Europe (Lavers and Villarini 2015). Because cutoff lows are in general getting more numerous every year (Muñoz et al. 2020), the frequency of heavy-precipitation events associated with the occurrence of cutoff lows may also be increasing around areas where the occurrence of upper-level lows is frequent, provided a more frequent arrival of moisture plumes to the leading edge of these lows. However, in the current context of global warming, there are regions with frequent cutofflow occurrence that are experiencing a precipitation deficit, such as central Chile, southeastern Australia and New Zealand, western North America, and northeast China (Nguyen et al. 2018). Therefore, evaluating the frequency of the arrival of moisture plumes to the leading edge of cutoff lows will be key to determining what to expect with regard to the likelihood of high-impact weather associated with a more frequent cutofflow occurrence.

Acknowledgments. We express our thanks to Professors Geraint Vaughan, Ann Webb, Suzanne Gray, and Bradford Barrett and to two anonymous reviewers for their comments on earlier versions of this paper. Author Muñoz was funded by the Agencia Nacional de Investigación y Desarrollo (ANID) through the Becas Chile program for Ph.D. researchers, Scholarship Number 72150517. Partial funding for author Schultz was provided by the Natural Environment Research Council Grants NE/I005234/1, NE/I026545/1, and NE/N003918/1 to the University of Manchester.

Data availability statement. Daily precipitation data are openly available from the Center for Climate and Resilience Research (CR2) (http://www.cr2.cl/datos-de-precipitacion/; last access: May 2020). Sounding data are openly available from the archive managed by the Department of Atmospheric Science of the University of Wyoming (http://weather.uwyo.edu/upperair/ sounding.html). NCEP-NCAR reanalysis data were provided by the NOAA/OAR/ESRL PSL (https://psl.noaa.gov/).

\section{REFERENCES}

Abatzoglou, J. T., 2016: Contribution of cutoff lows to precipitation across the United States. J. Appl. Meteor. Climatol., 55, 893-899, https://doi.org/10.1175/JAMC-D-15-0255.1. 
Al-Nassar, A. R., J. L. Pelegri, P. Sangra, M. Alarcon, and A. Jansa, 2020: Cutoff low systems over Iraq: Contribution to annual precipitation and synoptic analysis of extreme events. Int. J. Climatol., 40, 908-926, https://doi.org/10.1002/joc.6247.

American Meteorological Society, 2020: Atmospheric river. Glossary of Meteorology, http://glossary.ametsoc.org/wiki/ Atmospheric_river.

Ancellet, G., M. Beekmann, and A. Papayiannis, 1994: Impact of a cutoff development on downward transport of ozone in the stratosphere. J. Geophys. Res., 99, 3451-3463, https://doi.org/ 10.1029/93JD02551.

Antonescu, B., G. Vaughan, and D. M. Schultz, 2013: A five-year radar-based climatology of tropopause folds and deep convection over Wales, United Kingdom. Mon. Wea. Rev., 141, 1693-1707, https://doi.org/10.1175/MWR-D-12-00246.1.

Appenzeller, C., H. C. Davies, and W. A. Norton, 1996: Fragmentation of stratospheric intrusions. J. Geophys. Res., 101, 1435-1456, https://doi.org/10.1029/95JD02674.

Barahona, C., 2016: Precipitación asociada a bajas segregadas en el Hemisferio Sur (Rainfall associated with Southern Hemisphere cutoff lows). M.S. thesis, Departamento de Geofísica, Universidad de Chile, 180 pp.

Barrett, B. S., R. Garreaud, and M. Falvey, 2009: Effect of the Andes cordillera on precipitation from a midlatitude cold front. Mon. Wea. Rev., 137, 3092-3109, https://doi.org/10.1175/ 2009MWR2881.1.

—, D. B. Krieger, and C. P. Barlow, 2011: Multiday circulation and precipitation climatology during winter rain events of differing intensities in central Chile. J. Hydrometeor., 12, 1071-1085, https://doi.org/10.1175/2011JHM1377.1.

—, D. Campos, J. Vicencio, and R. Rondanelli, 2016: Extreme temperature and precipitation events in March 2015 in central and northern Chile. J. Geophys. Res. Atmos., 121, 4563-4580, https://doi.org/10.1002/2016JD024835.

— , G. Raga, A. Retama, and L. Christopher, 2019: A multiscale analysis of the tropospheric and stratospheric mechanisms leading to the March 2016 extreme surface ozone event in Mexico City. J. Geophys. Res. Atmos., 124, 4782-4799, https:// doi.org/10.1029/2018JD029918.

Blamey, R. C., A. M. Ramos, R. M. Trigo, R. Tomé, and C. J. Reason, 2018: The influence of atmospheric rivers over the South Atlantic on winter rainfall in South Africa. J. Hydrometeor., 19, 127-142, https://doi.org/10.1175/JHM-D-17-0111.1.

Bozkurt, D., R. Rondanelli, R. Garreaud, and A. Arriagada, 2016: Impact of warmer eastern tropical Pacific SST on the March 2015 Atacama floods. Mon. Wea. Rev., 144, 4441-4460, https:// doi.org/10.1175/MWR-D-16-0041.1.

Cordeira, J. M., F. M. Ralph, and B. J. Moore, 2013: The development and evolution of two atmospheric rivers in proximity to western North Pacific tropical cyclones in October 2010. Mon. Wea. Rev., 141, 4234-4255, https:// doi.org/10.1175/MWR-D-13-00019.1.

Davies, T. D., and E. Schuepbach, 1994: Episodes of high ozone concentrations at the earth's surface resulting from transport down from the upper troposphere/lower stratosphere: Review and case studies. Atmos. Environ., 28, 53-68, https://doi.org/ 10.1016/1352-2310(94)90022-1.

Doswell, C. A., 1987: The distinction between large-scale and mesoscale contribution to severe convection: A case study example. Wea. Forecasting, 2, 3-16, https://doi.org/10.1175/ 1520-0434(1987)002<0003:TDBLSA > 2.0.CO;2.

— H. E. Brooks, and R. A. Maddox, 1996: Flash flood forecasting: An ingredients-based methodology. Wea. Forecasting,
11, 560-581, https://doi.org/10.1175/1520-0434(1996)011<0560: FFFAIB $>2.0 . \mathrm{CO} ; 2$.

Falvey, M., and R. Garreaud, 2007: Wintertime precipitation episodes in central Chile: Associated meteorological conditions and orographic influences. J. Hydrometeor., 8, 171-193, https:// doi.org/10.1175/JHM562.1.

Favre, A., B. Hewitson, C. Lennard, R. Cerezo-Mota, and M. Tadross, 2012: Cutoff lows in the South Africa region and their contribution to precipitation. Climate Dyn., 41, 2331-2351, https://doi.org/ 10.1007/s00382-012-1579-6.

Fuenzalida, H. A., R. Sánchez, and R. D. Garreaud, 2005: A climatology of cutoff lows in the Southern Hemisphere. J. Geophys. Res., 110, D18101, https://doi.org/10.1029/2005JD005934.

Garreaud, R. D., and H. Fuenzalida, 2007: The influence of the Andes on cutoff lows: A modelling study. Mon. Wea. Rev., 135, 1596-1613, https://doi.org/10.1175/MWR3350.1.

—, M. Falvey, and A. Montecinos, 2016: Orographic precipitation in coastal southern Chile: Mean distribution, temporal variability, and linear contribution. J. Hydrometeor., 17, 1185-1202, https://doi.org/10.1175/JHM-D-15-0170.1.

Griffiths, M., M. J. Reeder, D. J. Low, and R. A. Vincent, 1998: Observations of a cutoff low over southern Australia. Quart. J. Roy. Meteor. Soc., 124, 1109-1132, https://doi.org/10.1002/ qj.49712454805.

Guan, B., and D. E. Waliser, 2015: Detection of atmospheric rivers: Evaluation and application of an algorithm for global studies. J. Geophys. Res. Atmos., 120, 12 514-12 535, https://doi.org/ 10.1002/2015JD024257.

—,- , and F. M. Ralph, 2018: An intercomparison between reanalysis and dropsonde observations of the total water vapor transport in individual atmospheric rivers. J. Hydrometeor., 19, 321-337, https://doi.org/10.1175/JHM-D-17-0114.1.

Hirota, N., Y. N. Takayabu, M. Kato, and S. Arakane, 2016: Roles of an atmospheric river and a cutoff low in the extreme precipitation event in Hiroshima on 19 August 2014. Mon. Wea. Rev., 144, 1145-1160, https://doi.org/10.1175/MWR-D-15-0299.1.

Holton, J. R., 2004: An Introduction to Dynamic Meteorology. 4th ed. Elsevier Academic Press, 535 pp.

Hoskins, B., M. E. McIntyre, and A. W. Robertson, 1985: On the use and significance of isentropic potential vorticity maps. Quart. J. Roy. Meteor. Soc., 111, 877-946, https://doi.org/ 10.1002/qj.49711147002.

Hu, K., R. Lu, and D. Wang, 2010: Seasonal climatology of cutoff lows and associated precipitation patterns over northeast China. Meteor. Atmos. Phys., 106, 37-48, https://doi.org/ 10.1007/s00703-009-0049-0.

Hughes, M., A. Hall, and R. G. Fovell, 2009: Blocking in areas of complex topography, and its influence on rainfall distribution. J. Atmos. Sci., 66, 508-518, https://doi.org/10.1175/ 2008JAS2689.1.

Johns, R. H., and C. A. Doswell, 1992: Severe local storms forecasting. Wea. Forecasting, 7, 588-612, https://doi.org/10.1175/ 1520-0434(1992)007<0588:SLSF > 2.0.CO;2.

Jusem, J., and R. Atlas, 1998: Diagnostic evaluation of vertical motion forcing mechanisms by using Q-vector partitioning. Mon. Wea. Rev., 126, 2166-2184, https://doi.org/10.1175/1520-0493(1998) 126<2166:DEOVMF>2.0.CO;2.

Kalnay, E., and Coauthors, 1996: The NCEP/NCAR 40-Year Reanalysis Project. Bull. Amer. Meteor. Soc., 77, 437-471, https://doi.org/10.1175/1520-0477(1996)077<0437:TNYRP> 2.0.CO;2.

Keyser, D., and M. A. Shapiro, 1986: A review of the structure and dynamics of upper-level frontal zones. Mon. Wea. Rev., 114, 
452-499, https://doi.org/10.1175/1520-0493(1986)114<0452: AROTSA $>2.0 . \mathrm{CO} ; 2$.

Lamjiri, M. A., M. D. Dettinger, F. M. Ralph, and B. Guan, 2017: Hourly storms characteristics along the U.S. West Coast: Role of atmospheric rivers in extreme precipitation. Geophys. Res. Lett., 44, 7020-7028, https://doi.org/10.1002/2017GL074193.

Lavers, D., and G. Villarini, 2015: The contribution of atmospheric rivers to precipitation in Europe and the United States. J. Hydrol., 522, 382-390, https://doi.org/10.1016/j.jhydrol.2014.12.010.

Massacand, A. C., H. Wernli, and H. Davies, 1998: Heavy precipitation on the Alpine southside: An upper-level precursor. Geophys. Res. Lett., 25, 1435-1438, https://doi.org/10.1029/ 98GL50869.

McNulty, R. P., 1978: On upper tropospheric kinematics and severe weather occurrence. Mon. Wea. Rev., 106, 662-672, https:// doi.org/10.1175/1520-0493(1978)106<0662:OUTKAS > 2.0.CO;2. , 1995: Severe and convective weather: A central region forecasting challenge. Wea. Forecasting, 10, 187-202, https://doi.org/ 10.1175/1520-0434(1995)010<0187:SACWAC $>2.0 . C O ; 2$.

Miky-Funatsu, B., M. A. Gan, and E. Caetano, 2004: A case study of orographic cyclogenesis over South America. Atmósfera, 17, 91-113.

Muñoz, C., D. M. Schultz, and G. Vaughan, 2020: A midlatitude climatology and interannual variability of $200-$ and $500-\mathrm{hPa}$ cutoff lows. J. Climate, 33, 2201-2222, https://doi.org/10.1175/ JCLI-D-19-0497.1.

Ndarana, T., and D. W. Waugh, 2010: The link between cutoff lows and Rossby wave breaking in the Southern Hemisphere. Quart. J. Roy. Meteor. Soc., 136, 869-885, https://doi.org/ 10.1002/qj.627.

Nguyen, P., A. Thorstensen, S. Sorooshian, K. Hsu, A. Aghakouchak, H. Ashouri, H. Tran, and D. Braithwaite, 2018: Global precipitation trends across spatial scales using satellite observations. Bull. Amer. Meteor. Soc., 99, 689-697, https://doi.org/10.1175/ BAMS-D-17-0065.1.

Nieto, R., and Coauthors, 2005: Climatological features of cutoff low systems in the Northern Hemisphere. J. Climate, 18, 3085-3103, https://doi.org/10.1175/JCLI3386.1.

- M. Sprenger, H. Wernli, R. M. Trigo, and L. Gimeno, 2008: Identification and climatology of cutoff lows near the tropopause. Ann. N. Y. Acad. Sci., 1146, 256-290, https://doi.org/ 10.1196/annals.1446.016.

Pinheiro, H. R., K. I. Hodges, M. A. Gan, and N. J. Ferreira, 2017: A new perspective of the climatological features of upperlevel cutoff lows in the Southern Hemisphere. Climate Dyn., 48, 541-559, https://doi.org/10.1007/s00382-016-3093-8.

Pizarro, J., and A. Montecinos, 2000: Cutoff cyclones off the subtropical coast of Chile. Preprints, Sixth Int. Conf. on Southern Hemisphere Meteorology and Oceanography, Santiago, Chile, Amer. Meteor. Soc., 301-303, https://ams.confex.com/ams/ other/techprogram/paper_11051.htm.

Porcù, F., A. Carrassi, C. M. Medaglia, F. Prodi, and A. Mugnai, 2007: A study on cutoff low vertical structure and precipitation in the Mediterranean region. Meteor. Atmos. Phys., 96, 121-140, https://doi.org/10.1007/s00703-006-0224-5.

Price, J. D., and G. Vaughan, 1992: Statistical studies of cutoff low systems. Ann. Geophys., 10, 96-102.

— , and - 1993: The potential for stratosphere-troposphere exchange in cutoff-low systems. Quart. J. Roy. Meteor. Soc., 119, 343-365, https://doi.org/10.1002/qj.49711951007.
Ralph, F. M., P. J. Neiman, and G. A. Wick, 2004: Satellite and CALJET aircraft observations of atmospheric rivers over the eastern North Pacific Ocean during the winter of 1997/98. Mon. Wea. Rev., 132, 1721-1745, https://doi.org/10.1175/ 1520-0493(2004)132<1721:SACAOO > 2.0.CO;2.

Reboita, M. S., R. Nieto, L. Gimeno, R. da Rocha, T. Ambrizzi, R. Garreaud, and L. F. Krügger, 2010: Climatological features of cutoff low systems in the Southern Hemisphere. J. Geophys. Res., 115, D17104, https://doi.org/10.1029/2009JD013251.

Romps, D. M., 2017: Exact expression for the lifting condensation level. J. Atmos. Sci., 74, 3891-3900, https://doi.org/10.1175/ JAS-D-17-0102.1.

Rondanelli, R., L. Gallardo, and R. D. Garreaud, 2002: Rapid changes in ozone mixing ratios at Cerro Tololo $\left(30^{\circ} 10^{\prime} \mathrm{S}\right.$, $70^{\circ} 48^{\prime} \mathrm{W}, 2200 \mathrm{~m}$ ) in connection with cutoff lows and deep troughs. J. Geophys. Res., 107, 4677, https://doi.org/10.1029/ 2001JD001334.

Rossby, C. G., 1932: Thermodynamics applied to air mass analysis. Pap. Phys. Oceanogr. Meteor., 1, 31-48 https://doi.org/10.1575/ 1912/1139.

Schultz, D. M., P. N. Schumacher, and C. A. Doswell, 2000: The intricacies of instabilities. Mon. Wea. Rev., 128, 4143-4148, https:// doi.org/10.1175/1520-0493(2000)129<4143:TIOI>2.0.CO;2.

Shepherd, M., T. Mote, J. Dowd, M. Roden, P. Knox, S. C. McCutcheon, and S. E. Nelson, 2011: An overview of synoptic and mesoscale factors contributing to the disastrous Atlanta flood of 2009. Bull. Amer. Meteor. Soc., 92, 861-870, https:// doi.org/10.1175/2010BAMS3003.1.

Singleton, A. T., and C. J. C. Reason, 2007: A numerical model study of an intense cutoff low pressure system over South Africa. Mon. Wea. Rev., 135, 1128-1150, https://doi.org/ 10.1175/MWR3311.1.

Tsuji, H., and Y. N. Takayabu, 2019: Precipitation enhancement via the interplay between atmospheric rivers and cutoff lows. Mon. Wea. Rev., 147, 2451-2466, https://doi.org/10.1175/ MWR-D-18-0358.1.

Valenzuela, R. A., and R. D. Garreaud, 2019: Extreme daily rainfall in central-southern Chile and its relationship with low-level horizontal water vapor fluxes. J. Hydrometeor., 20, 1829-1850, https://doi.org/10.1175/JHM-D-19-0036.1.

van den Broeke, M. S., D. M. Schultz, R. H. Johns, J. S. Evans, and J. E. Hales, 2005: Cloud-to-ground lightning production in strongly forced, low-instability convective lines associated with damaging wind. Wea. Forecasting, 20, 517-530, https:// doi.org/10.1175/WAF876.1.

Vaughan, G., B. Antonescu, D. M. Schultz, and C. Dearden, 2017: Invigoration and capping of a convective rainband ahead of a potential vorticity anomaly. Mon. Wea. Rev., 145, 2093-2117, https://doi.org/10.1175/MWR-D-16-0397.1.

Viale, M., R. Valenzuela, R. D. Garreaud, and F. M. Ralph, 2018: Impacts of atmospheric rivers on precipitation in southern South America. J. Hydrometeor., 19, 1671-1687, https:// doi.org/10.1175/JHM-D-18-0006.1.

Vuille, M., and C. Ammann, 1997: Regional snowfall patterns in the high, arid Andes. Climatic Change, 36, 413-423, https:// doi.org/10.1023/A:1005330802974.

Wernli, H., and M. Sprenger, 2007: Identification and ERA-15 climatology of potential vorticity streamers and cutoffs near the extratropical tropopause. J. Atmos. Sci., 64, 1569-1586, https://doi.org/10.1175/JAS3912.1. 